\title{
Factors Controlling the Abundance of Rainbow Trout in the Colorado River in Grand Canyon in a Reach Utilized by Endangered Humpback Chub
}

\begin{tabular}{|r|l|}
\hline Journal: & Canadian Journal of Fisheries and Aquatic Sciences \\
\hline Manuscript ID & cjfas-2015-0101.R1 \\
\hline Manuscript Type: & Article \\
\hline Date Submitted by the Author: & 31 -Jul-2015 \\
\hline Complete List of Authors: & $\begin{array}{l}\text { Korman, Josh; Ecometric Research Inc. } \\
\text { Yard, Micheal; Grand Canyon Monitoring and Research Center, } \\
\text { Yackulic, Charles; USGS, Grand Canyon Monitoring and Research Center }\end{array}$ \\
\hline Keyword: & $\begin{array}{l}\text { DAMS < Environment/Habitat, FRESHWATER FISHERIES < General, } \\
\text { General }\end{array}$ \\
\hline
\end{tabular}


1 Factors Controlling the Abundance of Rainbow Trout in the

2 Colorado River in Grand Canyon in a Reach Utilized by

3 Endangered Humpback Chub

4

5 Josh Korman ${ }^{1}$, Michael D. Yard ${ }^{2}$, and Charles B. Yackulic ${ }^{2}$

6

$7 \quad{ }^{1}$ Ecometric Research Inc., $3560 \mathrm{~W} 22^{\text {nd }}$ Ave., Vancouver, BC V6S 1J3, Canada.

8 jkorman@ecometric.com

$9 \quad{ }^{2}$ U.S. Geological Survey, Southwest Biological Science Center, Grand Canyon Monitoring and

10 Research Center, 2255 N. Gemini Dr., Flagstaff, AZ 86001, USA. myard@,usgs.gov,

11 cyackulic@usgs.gov

12

13 July $31^{\text {st }}, 2015$

14 


\section{Abstract}

We estimated the abundance, survival, movement, and recruitment of non-native rainbow

17 trout in the Colorado River in Grand Canyon to determine what controls their abundance near the

18 Little Colorado River (LCR) confluence where endangered humpback chub rear. Over a 3-year

19 period, we tagged more than 70,000 trout and recovered over 8,200 tagged fish. Trout density

20 was highest $(10,000-25,000 \mathrm{fish} / \mathrm{km})$ in the reach closest to Glen Canyon Dam where the

21 majority of trout recruitment occurs, and was 30-50-fold lower (200-800 fish/km) in reaches near

22 the LCR confluence $\sim 100 \mathrm{~km}$ downstream. The extent of rainbow trout movement was limited

23 with less than $1 \%$ of recaptures making movements greater than $20 \mathrm{~km}$. However, due to high

24 trout densities in upstream source areas, this small dispersal rate was sufficient to explain the 3-

25 fold increase in the relatively small population near the LCR. Reducing dispersal rates of trout

26 from upstream sources is the most feasible solution to maintain low densities near the LCR to

27 minimize negative effects of competition and predation on humpback chub.

28

29 Keywords: movement; population dynamics; regulated rivers; mark-recapture; non-native 30 species 
Introduction

Native fish are commonly threatened by increased competition and predation from nonnative fish (Strayer 2010). This issue is of particular concern in regulated rivers, where changes in physical characteristics of the stream environment often promote the establishment of nonnatives and modify interactions among fishes (Olden 2006; Sabo et al. 2010). Effective control of non-native populations requires an understanding of recruitment, survival, movement, and growth which determines their abundance and size-structure in areas where they interact with native species. Annual variation in recruitment of non-natives will determine long-term trends in population abundance. Adult mortality and dispersal often determine the persistence of abundant population dynamics that control the abundance of rainbow trout (Oncorhynchus mykiss) in the populations following large recruitment events. Growth rates control fecundity and future reproductive success and also the size-structure of the population, which can influence competition and predation effects. Movement patterns of non-native fish may be important if they are produced in locations that are distant from areas used by native fish.

In this manuscript, data from a large-scale mark-recapture study is used to quantify the Colorado River near the confluence of the Little Colorado River where endangered humpback chub (Gila cypha) rear. Rainbow trout were introduced below Glen Canyon Dam beginning in 1964 shortly after dam closure. Changes in the flow regime from the dam beginning in the early 1990's, intended to improve the status of native and iconic humpback chub and restore sand bars (Bureau of Reclamation 1995), inadvertently led to an increase in natural reproduction of rainbow trout (McKinney et al. 2001; Korman et al. 2012). Although this increase was beneficial to the blue ribbon trout fishery in the $25 \mathrm{~km}$-long Glen Canyon tailwater located immediately below the dam (Fig. 1), it was later recognized as being potentially detrimental to humpback chub (Coggins et al. 2011). Humpback chub is a warmwater species, and the majority of the population in Grand Canyon spawns in the Little Colorado River (LCR) that enters $125 \mathrm{~km}$ downstream of Glen Canyon Dam. Some juveniles produced in the LCR emigrate to the mainstem Colorado River and rear in colder and clearer water relative to pre-impoundment conditions. Non-native rainbow and brown trout compete and prey on juvenile humpback chub in this critical rearing area (Marsh and Douglas 1997; Yard et al. 2011; Cross et al. 2011), which 
61 in turn leads to reductions in their growth and survival rates (C. Yackulic, U.S. Geological

62 Survey, unpublished data).

No directed field studies have been conducted to determine the provenance of rainbow trout found near the LCR confluence. Rainbow trout are broadly distributed over more than 400

$65 \mathrm{~km}$ of the Colorado River between Glen Canyon Dam and Lake Mead. Trout densities below the LCR are typically very low except near a few coolwater perennial tributaries located a minimum of $40 \mathrm{~km}$ downstream of the LCR (Makinster et al. 2010). Catch rates of rainbow trout between Glen Canyon Dam and the LCR confluence decrease with increasing distance from the dam and juvenile trout are rare downstream of the confluence with the Paria River (Coggins 2008, Fig. 1). Rainbow trout spawn throughout the perennially-clear Glen Canyon tailwater located upstream of the Paria River confluence (Korman et al. 2011), and used to spawn in Nankoweep Creek, located approximately $15 \mathrm{~km}$ upstream of the LCR confluence (Valdez and Carothers 1998). A large flood in the late 1990's blocked spawner access from the mainstem and eliminated this tributary as source of juvenile production. These observations suggest that the majority of rainbow trout near the LCR now originate almost exclusively from the Glen Canyon tailwater. However, because the rainbow trout population near the LCR is small, relatively limited amounts of local reproduction near the LCR could be sufficient to sustain or partially sustain trout abundance in this location. A more thorough analysis of the electrofishing data using a stock synthesis model indicated that local recruitment does contribute to the population of trout in the mainstem between the Paria and LCR confluences (Korman et al. 2012), but predictions depended on a number of untested assumptions regarding catchability, growth, and the extent of process and observation error.

Identifying the factors that control the abundance and size structure of rainbow trout near the LCR, and effects of trout on humpback chub, are the most critical information needs of the Glen Canyon Dam Adaptive Management program (GCDAMP; Walters et al. 2000; Melis et al.

87 (Coggins and Walters 2009), fluctuations from Glen Canyon Dam were increased in 2003-2005 to limit rainbow trout recruitment in Glen Canyon (Korman et al. 2011), and a four-year largescale mechanical removal program near the LCR was implemented between 2003 and 2006

90 (Coggins et al. 2011). The efficacy of such control programs depend completely on the population dynamics of the target species. Reducing recruitment of rainbow trout in Glen 
92 Canyon via flow changes may not have substantive effects on abundance of trout at the LCR if 93 there are significant sources of local reproduction downstream of Glen Canyon. If dispersal from 94 Glen Canyon is density dependent, limiting downstream dispersal through flow changes may 95 only be required in very high recruitment years, and annual reductions in trout recruitment will 96 unnecessarily impact the trout fishery in Glen Canyon. In the long-term, removal programs near

97 the LCR will be ineffective if there is a constant source of immigration from upstream sources, or at the least, the level of removal effort would need to be adjusted if immigration rates are 99 known.

Recognizing that the existing electrofishing catch-per-effort program was not sufficient to

101

102

103

104 determine the provenance of trout near the LCR and the causes for potential downstream movement, the GCDAMP supported the implementation of a multi-year large-scale mark recapture program. In this paper, we apply novel analytical approaches to estimate abundance, survival, and movement of rainbow trout based on data from this program, with the ultimate objective of determining the contribution of emigrants from upstream sources to trends in trout abundance at the LCR. In a companion paper (Yard et al. this issue), we use the mark-recapture data to describe seasonal and spatial patterns in trout growth, which is combined with lengthfrequency data to support inferences regarding the timing of movement from Glen to Marble Canyon, and identify factors that potentially drive trout dispersal. These two papers provide an unprecedented description of the population dynamics of a resident non-native fish species in a large regulated river owing to the extensive scale of the mark-recapture program. Over three years, more than 190,000 rainbow trout were captured in a $130 \mathrm{~km}$-long section of the Colorado River; $13-19 \%$ of the shoreline within the study area was sampled on each of 16 trips; more than 70,000 rainbow trout were marked with a Passive Integrated Transponder (PIT) tag that provided unique identification of individuals; and over 8,200 of these fish were recaptured three months or more after release.

\section{Methods}

\section{Study Area}

Our study area extends from Glen Canyon Dam (thalweg river kilometer (rkm) 0) to 5 $\mathrm{km}$ below the confluence of the Little Colorado River (rkm 130, Fig. 1). Given the observation of decreasing catch rates of rainbow trout over the study area, we distributed our sampling effort 
123

124

125

126

127

128

129

130

131

132

133

134

135

136

137

138

139

140

141

142

143

144

145

146

147

148

149

150

151

152

153

across four reaches spaced approximately evenly between the dam and the LCR. We also sampled a reach just below the LCR given its high use by juvenile humpback chub and potential effects of turbidity from the LCR on rainbow trout abundance in this area. The names and river km for each reach are: I) rkm 16.3-21.7; II) rkm 52.8-58.3); III) rkm 86.6-91.9; IVa) rkm 122.0123.6; and IVb) rkm 127.1-129.6. Reach I is assumed to represent conditions throughout the Glen Canyon tailwater, which extends from the dam to the confluence with the Paria River, and is wide, shallow, and low-gradient. Marble Canyon is $100 \mathrm{~km}$ long and extends from the Paria River to the confluence with the LCR. Reaches II, III, and IVa are assumed to represent conditions in upper, middle, and lower Marble canyon, respectively. Sampling reaches in this section are steeper and more confined than in Glen Canyon. Occasional large inputs of fine sediment from the Paria River result in short-term increases in turbidity (Fig. S1) and a higher proportion of fines in gravel and cobble substrates relative to Glen Canyon. Reach IVb is intended to represent conditions in what is known as the LCR inflow reach, a section of the mainstem extending from the LCR confluence to $1.5 \mathrm{~km}$ downstream of our study area. Reach $\mathrm{IVb}$ is affected by sediment inputs from both the Paria and the LCR and is therefore more frequently turbid. Reaches IVa and IVb are part of the most significant rearing area for juvenile humpback chub in the mainstem Colorado River below Glen Canyon Dam (Gloss and Coggins 2005).

\section{Sampling}

Nighttime boat electrofishing was used to sample rainbow trout. We conducted four 'Downstream' sampling trips per year in April, July, September, and January from April 2012 through September 2014 (11 trips) where all five study reaches were sampled over a 14-day period. Two nights of sampling effort were conducted in each of the first 4 reaches, with the remaining 8 nights spent in reach IVb. The total shoreline distance on each bank for reaches I-III was $6 \mathrm{~km}$ long. We sampled the upper $4 \mathrm{~km}$ on night 1 and the lower $4 \mathrm{~km}$ sampled on night 2 (Fig. 2). Thus, the upper and lower 2-km buffer sections were sampled once per trip, while the central $2-\mathrm{km}$ robust design sections were sampled twice ( 2 passes of effort). Reaches IVa and $\mathrm{IVb}$ were shorter and were 2.0 and $2.25 \mathrm{~km}$ long, respectively, and were sampled in their entirety each night for two consecutive nights. Electrofishing effort (pulsed DC at $\sim 4500 \mathrm{~W}$ ) on the first two passes for all reaches was completed at a pace of approximately 3 seconds per meter of shoreline. Additional sampling in reach IVb was conducted to support an existing mark- 
154 155

recapture study of juvenile humpback chub, but catches from this effort included rainbow trout and were used in this analysis. The additional sampling in IVb consisted of 3 passes of slowpaced electrofishing ( 4.3 seconds per meter) to maximize catch of small humpback chub, and required two nights of effort to cover the reach on each pass. In addition, a total of 90 hoop nets (6 mm mesh; 0.5-m diameter x 1-m long) were deployed along the shoreline in this reach and checked daily for 8 consecutive days. As described below, rainbow trout catches in reach IVb from the juvenile chub component of the study were integrated with data from the $1^{\text {st }}$ two passes.

All five study reaches were divided into 250 -m shoreline sites on each bank and were identified in the field by reflective markers (Fig. 2). River-left and river-right sites were sampled by separate boat electrofishing crews consisting of a boatman and netter. The netter captured stunned fish with a long-handled dipnet and fish were held in aerated 40-L buckets. We averaged 12 minutes of electrofishing effort per 250-m site. A tender boat transported fish to a central processing location and returned them to the center of the original $250-\mathrm{m}$ site of capture after processing.

At the central processing location buckets of incoming fish were kept on the beach and aerated and flushed with water to maintain adequate water quality. Groups of 10-15 fish were anesthetized with clove oil. Fork length and weight were recorded to the nearest $\mathrm{mm}$ and gram for fish $>150 \mathrm{~mm}$, and $0.1 \mathrm{~g}$ for smaller fish. All fish $\geq 75 \mathrm{~mm}$ were scanned for a PIT tag and checked for the presence of a fin clip. Due to logistic and cost limitations, we were unable to PIT tag all rainbow trout in reaches with high densities. We therefore only PIT-tagged trout captured in the central $2 \mathrm{~km}$ of reaches I-III up to a maximum of approximately 750-1000 fish over the two-day sampling period in each reach. Fish below $75 \mathrm{~mm}$, and fish $\geq 75 \mathrm{~mm}$ in excess of this 750-1000 limit were given a fin clip that allowed us to determine whether the fish had been previously captured within the current trip. We rotated the location of fin clips across trips (upper caudal, lower caudal, and anal fins) to reduce the probability of determining that a recaptured fish with a fin clip was a within-trip recapture when it was actually marked on a previous trip. As well, only fish with "fresh looking" fin clips (very straight edge of clip) were counted as recaptures. During early trips when catches were very high in reaches I and II, we were unable to clip all trout captured in the robust design section that exceeded the maximum PIT-tagging limit. Thus, some fish were captured and released in these sections without a mark. Following processing, fish were held in aerated 40-L buckets for a minimum of 30 minutes prior to their 
185

186

187

188

189

190

191

192

193

194

195

196

197

198

199

200

201

202

203

204

205

206

207

208

209

210

211

212

213

214

215

return to the site of capture. Tagged fish that died or did not look healthy after the holding period were euthanized and their tag ID was recorded so it could be removed from the list of live releases. Total time from capture to release typically ranged from 1-2 h.

We conducted 24-h holding experiments each trip to estimate the PIT-tag shedding rate and mortality rate due to capture and processing. A random sample of 25-40 rainbow trout processed from each of four sites within a reach on night 1 were held in separate 120-L plastic containers which were suspended at the water surface using a PVC frame which was anchored to shore. The containers were perforated with holes that were large enough to allow water to circulate but not let small fish escape. Fish were removed from the enclosures after $24 \mathrm{~h}$, anesthetized, measured, weighed, scanned, and returned to their original capture site. We calculated the fraction of fish that had shed their tag, died, or both. The total tag loss proportion (shed + mortality) for each reach and trip was used to adjust the number of PIT tags released in each reach by trip. We were generally unable to conduct holding experiments in reach IVb owing to low densities of rainbow trout and therefore used the tag loss proportions from IVa on each trip as a surrogate for losses in IVb.

In addition to the four downstream trips conducted each year where all five reaches were sampled, we also conducted one or two sampling trips each fall to sample all of the $25 \mathrm{~km}$ length of Glen Canyon. The initial objective of these trips was to mark 10,000 age-0 trout each year. As the study progressed, however, we were unable to meet this target and therefore tagged fish of all ages. Glen Canyon trips were conducted in fall when a sufficient fraction of the annual age-0 cohort had reached a size large enough to PIT tag $(\geq 75 \mathrm{~mm})$, thereby increasing our chances of detecting emigration from Glen Canyon. Fish were collected from 250-m shoreline sites and PIT tagged following the protocols for downstream trips described above. However, we employed slow speed electrofishing to maximize catches of smaller rainbow trout. Due to exceptionally high age-0 fish abundance in 2011, a single 10-day trip conducted in November 2011 was sufficient to mark over 11,000 age-0 trout in Glen Canyon in addition to 1,000 fish in a 6-km section below the Paria River. Due to much lower recruitment in 2012-2014, two 10-day trips, conducted in October and December were required to meet or almost meet the 10,000 fish target for Glen Canyon, and only approximately $25 \%$ of the fish tagged were age- 0 . We conducted five fall Glen Canyon trips and 11 downstream trips over the study period.

\section{Jolly-Seber Model}


216

217

218

219

220

221

222

223

224

225

226

227

228

229

230

231

232

233

234

235

236

237

238

239

240

241

242

243

244

245

246

We use a modified version of an open population Jolly-Seber model implemented in a robust design framework to estimate abundance, recruitment, survival, and capture probability of rainbow trout $\geq 75 \mathrm{~mm}$ in each reach. The standard Jolly-Seber model estimates apparent survival and capture probability based on the attrition of marked cohorts across primary sampling periods. Abundance is estimated based on the sum of the estimates of the number of marked fish that are alive and the unmarked population which depends on the unmarked catch and the estimated capture probability. Recruitment is determined based on differences in abundance across sampling intervals taking into account the estimated apparent survival. That is, recruitment between trip intervals $i$ and $i+1\left(\mathrm{R}_{\mathrm{i}-\mathrm{i}+1}\right)$ is the differences between the abundance on trip $i+1$ $\left(\mathrm{N}_{\mathrm{i}+1}\right)$ and the product of abundance on trip $i\left(\mathrm{~N}_{\mathrm{i}}\right)$ and apparent survival $\left(\mathrm{AS}_{\mathrm{i}-\mathrm{i}+1}\right)$ between the trips $\left(\mathrm{R}_{\mathrm{i}-\mathrm{i}+1}=\mathrm{N}_{\mathrm{i}+1}-\mathrm{N}_{\mathrm{i}} \cdot \mathrm{AS}_{\mathrm{i}-\mathrm{i}+1}\right)$. Uncertainty in model parameters depends in part on the extent of confounding between apparent survival and capture probability estimates. To some extent, the observed number of marks recaptured may be explained by higher survival between trips and low capture probability, or lower survival and high capture probability. Robust design models reduce the extent of this confounding because they assume the population is closed over shorter secondary sampling periods that occur within primary sampling periods. By assuming a relationship between the capture probabilities in secondary and primary sampling periods, certainty in the capture probability estimates is increased, which in turn leads to greater certainty in apparent survival, abundance, and recruitment estimates.

Our Jolly-Seber model is applied to rainbow trout $\geq 75 \mathrm{~mm}$ in the robust design sections of each study reach using data from only the 11 downstream trips. 'Robust design' sections are those sampled more than once per sampling trip (i.e., have secondary sampling periods), which includes the central 2-km sections of reaches I-III and all of reaches IVa and IVb. The primary sampling periods are downstream trips (approximately 3 months apart) and the secondary sampling periods are passes of effort within each trip (one day apart in reaches I-IVa and one or two days apart in reach IVb). Recall that two passes (nights) of effort per trip were conducted in reaches I-IVa. A total of five passes of effort per trip were conducted in IVb, which consisted of two passes of normal speed electrofishing conducted over the 1st two consecutive nights, followed by 3 passes of slow-speed electrofishing conducted over the next 6 nights. All five passes include catches from hoop nets fished over the nights associated with each electrofishing pass. 
The model we developed is similar to the robust design Jolly-Seber model described in Williams et al. (2001) with exceptions to address unique aspects of our sampling design and to improve the likelihood function used to fit the model. A full description of the model is provided in the supplement. There are four unique aspects of our model we highlight here:

1. We separate mortality and movement losses in the computation of apparent survival, whose effects are normally confounded. Apparent survival used to predict the attrition of marked and unmarked cohorts over time in the model is the product of the fraction of fish surviving from one trip to the next and the proportion of fish that remain in the robust design section across trips (the residency proportion pRes, whose computation is described in the movement section below).

2. Our model uses temporary marks (fin clips) to provide additional information on withintrip capture probability. As well, fish that are released and recaptured within the same trip (within-trip recaptures) are allowed to have a different capture probability compared to those that are recaptured for the first time on a given trip (across-trip recaptures). To simplify the estimation, we use a standard parametric function to relate these two types of capture probabilities (as in Williams et al. 2001). Within-trip capture probabilities for each primary sampling period (trip) are estimated based on the proportion of both PITtagged and fin-clipped fish recaptured on secondary sampling periods (passes) that were initially released on previous passes within a given primary period. Marks in the latter group are only used in the computation of within-trip capture probability as fins can regenerate and do not provide a reliable means of determining whether a fish was released on a previous trip. These temporarily-marked fish are therefore re-assigned to the unmarked population at the end of each primary sampling period.

3. We account for previously captured fish that were not given a mark in the prediction of the catch of unmarked fish after pass 1 . On the first 7 downstream trips in reaches I and II we were not able to PIT-tag or fin clip all fish captured within the robust design section due to logistical limitations. Our model, tracks the abundance of this previously captured but unmarked cohort across passes within trips. This is needed so that a within-trip capture probability can be used to predict the catch of unmarked but previously captured fish, which is combined with the prediction of unmarked not-previously captured fish (based on the across-trip capture probability) to determine the total catch of unmarked 
fish. As for temporarily marked fish, the unmarked but previously caught fish are reassigned to the population of fish that have never been captured at the end of each primary sampling period.

4. We use a negative binomial likelihood, rather than the traditional multinomial error structure (Williams et al. 2001), to fit our model. The negative binomial distribution directly accounts for overdispersion in the data thereby producing unbiased estimates of variance and statistics that depend on that variance (confidence intervals, Akaike's Information Criteria (AIC)) compared to the multinomial model if overdispersion is present in the model fit (Burnham and Anderson 2002). Our approach avoids the need to use post-fit variance adjustments which can be problematic (c-hat, Burnham and Anderson 2002).

Parameters of the model were estimated by maximum likelihood using the nonlinear search procedure in AD model-builder (ADMB; Fournier et al. 2011). We compared four alternate model structures. Survival rate was allowed to vary between trip intervals (denoted as model $\mathrm{S}_{\mathrm{t}}$ ) or held constant over all intervals (model $\mathrm{S}_{\mathrm{o}}$ ). Capture probabilities were always allowed to vary by trip and pass but we used two alternate structures to account for effects of previous capture within a trip. Model $\mathrm{P}_{\mathrm{t}}$ assumes equal capture probability for fish previously captured and not previously captured within the trip, while model $\mathrm{P}_{\mathrm{tb}}$ allows different capture probabilities for these two groups. The latter model estimates the parameter $\beta$, which determines the relative difference between across- and within-trip capture probabilities, while the former model fixes $\beta$ at 0 (see equations 4 and 5 in Table S2). We evaluate the support for the four combinations of these models $\left(\mathrm{P}_{\mathrm{t}}-\mathrm{S}_{\mathrm{o}}, \mathrm{P}_{\mathrm{tb}}-\mathrm{S}_{\mathrm{o}}, \mathrm{P}_{\mathrm{t}}-\mathrm{S}_{\mathrm{t}}, \mathrm{P}_{\mathrm{tb}}-\mathrm{S}_{\mathrm{t}}\right)$ using AIC. Models within 0-2 AIC units of the most parsimonious model (the one with the lowest AIC) were considered to have strong support; models within 2-7 units were considered to have moderate support, and models that had AIC values $>7$ units relative to the best model were considered to have weak support (Burnham and Anderson 2002).

We computed the relative immigration rate for each reach and trip interval based on the ratio of the estimated new recruits between trip intervals to the abundance estimate at the end of the interval, and then averaged these values across trips. This statistic represents the average number of immigrants per resident, and quantifies the transitory nature of the population in each reach. We also estimated total abundance of rainbow trout over the entire study area for each trip 
based on estimates of fish density in the robust design sections of each reach from the JollySeber model. We assumed that the density in reach I represented the density throughout Glen Canyon. A spatially-explicit Jolly-Seber model for Glen Canyon that used data from reach I as well as data from full Glen Canyon trips indicates that reach I represents the typical density throughout the reach (Korman and Yard, unpublished data). We also assumed that trout density in reach $\mathrm{IVb}$ represented densities from the LCR to the bottom of reach IVb. This assumption is reasonable given the total distance of this segment is only $6.5 \mathrm{~km}$ and catch rates from a previous study were relatively consistent over this section (Coggins 2008). We used linear interpolation to estimate fish density for each river km between Lees Ferry and the LCR. Historical electrofishing catch rates indicate a decreasing trend in abundance over the length of Marble Canyon (Makinster et al. 2010), and assuming a linear trend between reaches is the simplest model to interpolate densities. We summed the interpolated density values to estimate the total abundance in Glen Canyon (rkm 0-25); Upper Marble Canyon (km 25-58); middle Marble Canyon (rkm 58-92); Lower Marble Canyon (rkm 92-125); and the LCR inflow reach (rkm 125130, Fig. 1).

\section{Movement}

Upstream and downstream movement of rainbow trout was calculated as the difference between the river $\mathrm{km}$ for the site where a PIT-tagged fish was initially captured and released, and the river $\mathrm{km}$ for the site where it was later recaptured in. Observed movement distances were grouped for each release-recapture trip combination (hereafter referred to as 'release-recapture' strata), which included a strata for fish released and recaptured on the same trip. Fitting parametric distributions to observed movement distances facilitates comparison of movement patterns among reaches and trip intervals, and can also be used to derive estimates of emigration losses for the Jolly-Seber model we use to estimate demographic parameters. We fit Cauchy distributions to observed movement distances for each release-recapture trip strata. The Cauchy distribution is a common model used to predict dispersal in animal populations (Muneepeerakul et al. 2008). Parameters were estimated by maximum likelihood using the fitdistr function from the MASS library in R (Venebles and Ripley 2002). Prior to fitting these distributions, each observed movement distance was weighted based on the inverse probability of detecting that movement distance. The probability of observing a movement distance will vary across reaches and release-recapture strata because it depends on the distribution of marked trout released 
340

341

342

343

across sites as well as spatial and temporal variation in sampling effort and capture probability on subsequent trips. The appendix provides a description of the computation of movement distance observation probabilities used to weight the data and examples of their effects on estimated movement distributions.

Cauchy movement distributions were used to compute the proportion of marked fish released in robust design sections on each trip that remain in those sections on subsequent trips. These 'residency proportions' were used in the Jolly-Seber model to separate the estimated apparent survival rate into losses due to mortality and movement. Residency proportions (pRes) for each release-recovery trip pairing were computed as follows: 1) calculate the distance of each release site to the upstream and downstream boundary of the robust design section; 2) use the estimated Cauchy distribution for a given release-recapture strata for each reach to determine the proportion of marked fish from each release site that will move upstream and downstream distances that exceed the distances to the boundaries of the robust design section; 3) multiply the number of marked fish released in each site by the sum of the upstream and downstream loss proportions to determine how many marked fish released in each site on a given release trip will emigrate out of the robust design section of the reach; and 4) sum the loss of marked fish from the robust design section across all sites, and compute $\mathrm{pRes}$ as one minus the ratio of all marked fish lost to the total marked fish released across sites. The key assumptions in the estimation are that the probability of moving various distances is the same for all sites within the robust design section and can be approximated using a Cauchy distribution (see results). The number of movement observations (recaptures) typically declined as the duration between release and recapture trips increased. Cauchy distributions for release-recovery combinations were only estimated for strata with 10 or more recaptures. The pRes estimates from the last releaserecovery strata that met this minimum sample size were used for cases with fewer than 10 recaptures.

A primary goal of our study is to determine the contribution of emigrants from Glen and Marble Canyons to the trends in abundance in reaches near the LCR. To do this, we developed a Bayesian across-reach movement model that used observations of the number of within- and across-reach recaptures and estimates of survival and capture probability from the Jolly-Seber model to determine the proportion of fish moving various distances from each source reach. These predictions were combined with the spatially-interpolated estimates of abundance 
371 described above to determine the number of fish emigrating to reaches near the LCR. The

372 observed proportion of tagged fish released in a source reach and recaptured in another reach on

373 later trips, relative to the total recaptures of trout released in the source reach, depends on the

374 actual proportion of fish moving to each reach as well as differences in capture probability and

375 survival among reaches. For example, fish moving to a reach with lower survival or lower 376 capture probability will be under-represented in the sample relative to fish that remain in the 377 source reach. The model we developed accounts for these effects to provide unbiased estimates 378 of the proportion of marked fish remaining in the source reach or moving to other reaches.

The across-reach movement model begins by computing the proportion of marked trout remaining in the source reach or moving to other reaches using a Cauchy distribution that determines the probability of moving various distances in upstream and downstream directions. We then distribute the known number of marked fish released on each trip in a source reach across the five reaches that were sampled based on proportions determined by the Cauchy distribution. This redistribution is assumed to occur between the release trip and the next recovery trip. The number of marked fish available for recapture on recovery trips is determined based on the product of the numbers alive from the previous trip and the apparent survival rate (previously estimated from the Jolly-Seber model). Recaptures are then predicted based on the product of the predicted number of marked fish available on each trip in each reach and reachand trip-specific capture probabilities (previously estimated by the Jolly-Seber model). The predicted proportion of recaptures from the source reach in each of the five reaches over all trips is computed and compared to the observed number of recaptures using a multinomial likelihood. of the movement distance Cauchy distribution, respectively. Parameters were estimated separately for each source reach. Posterior distributions of survival and trip-specific capture probability used in the Bayesian movement model were defined prior to running that model based on the maximum likelihood and variance estimates from the Jolly-Seber model. Due to the limited number of across-reach recaptures (see results), we did not attempt to model time dependency in the movement distributions, though this is a logical extension of the model. The model was programmed in WinBUGS (Sturtz et al. 2005), which uses Markov Chain Monte Carlo (MCMC) to estimate posterior distributions of parameter values and derived variables (immigration to LCR reaches). To achieve adequate convergence, as assessed by the Gelman- 
402 Rubin convergence statistic (Gelman et. al. 2004, $\hat{r}<1.05$ ), we saved every $5^{\text {th }}$ MCMC sample 403 from total of 5,000 for each of 3 chains initialized with random starting values, after discarding 404 the first 3,000 samples to eliminate initialization effects. The WinBUGS code for the Bayesian 405 across-reach movement model is provided in Table S3.

We used the across-reach movement model to evaluate whether the recruitment of rainbow trout to reaches near the LCR (IVa and IVb) estimated by the Jolly-Seber model could be explained by immigration from upstream sources. Predicted immigration was computed by integrating immigration predictions over space and time using posterior distributions of abundance and movement probabilities. We first estimated the abundance for each trip and $\mathrm{km}$ over the study area by linear interpolation of abundance estimates from the Jolly-Seber model. As described above, we added two break-points to the interpolation to account for effects of the Paria and LCR on trout densities. We assumed that density was uniform throughout Glen Canyon and equivalent to the estimates from reach I, and uniform between the LCR and the bottom of the study area and equivalent to the estimates for reach IVb. We then divided the area upstream of reach IVb into 4 sections (rkm 0-25 km, 25-73 km, 73-122 km, and 122-125 km) that we assumed were represented by the Cauchy movement distributions estimated for source reaches I, II, III, and IVa, respectively. The predicted immigration from each $\mathrm{km}$ within a section to reach $\mathrm{IVa}$ and $\mathrm{IVb}$ was determined based on the product of the interpolated abundance in that $\mathrm{km}$ and the probability of moving from that $\mathrm{km}$ to reach IVa and IVb as determined by the Cauchy movement distance distribution. This calculation included uncertainty in the interpolated density as determined by uncertainty in the reach-specific population estimates, and uncertainty in the shape of the Cauchy distribution computed internally in the across-reach movement model. The calculation was repeated for each $\mathrm{km}$ upstream of reach IVa and IVb, and values were summed within source sections. Immigration estimates were made for each trip interval, and summed across intervals and source sections to determine the total immigration to reaches IVa and IVb over the study period. These 'upstream source' estimates of immigration were compared to estimates of recruitment to reaches IVa and IVb determined independently by the Jolly-Seber model. We refer to these latter values as 'within-reach' estimates of immigration (W) as they depend only on the data collected in these reaches, in comparison to 'upstream source' estimates (U) which depend on abundance and movement rates from upstream reaches based on the acrossreach movement model. 
434 Results

435 Catch and Tagging Data

436 We captured more than 190,000 rainbow trout over 16 trips between November 2011 and 437 September 2014, and PIT-tagged 70,660 individuals (Table 1). Sixty percent of PIT-tagged 438 individuals were from Glen Canyon owing to the additional fall sampling trips which covered its 439 entire 25-km length. We recaptured 8,231 PIT-tagged fish that were at large for one or more 440 months (across-trip recaptures), which represents $11.6 \%$ of the total number of tagged releases.

441 Over 22,000 PIT-tagged or fin-clipped trout released in the robust design sections across the five 442 reaches and 11 downstream trips were available for capture on subsequent passes within trips. A 443 total of $7 \%, 11 \%, 15 \%, 25 \%$, and $11 \%$ of these marked trout were recaptured on secondary 444 sampling periods (passes 2+) in reaches I, II, III, IVa, and IVb, respectively (within-trip 445 recaptures). Latent mortality of tagged trout due to capture and handling and loss of PIT tags due 446 to shedding and failure was low. Across all trips and reaches, we held over 4,400 tagged trout in 44771 different 24-h trials (Table 2). The combined tag loss due to mortality and shedding averaged 448 449 450 $4.5 \%$ and was reasonably consistent across trips $(\mathrm{SE}=3.9 \%)$.

The presence of age- 0 trout and their recruitment to larger size classes as seen from length-frequency distributions provides evidence for local recruitment in reaches downstream of Glen Canyon. In Glen Canyon, rainbow trout that are 6 months old (from hatch) average $80 \mathrm{~mm}$

452 in length based on counts of daily otolith increments (Korman et al. 2011), and age-1 trout are

$453130 \mathrm{~mm}$ based on growth rates determined from this study (Yard et al., this issue). A comparison 454 of length-frequencies across reaches and trips indicated that most age- 0 fish are produced in 455 reach I and very few small rainbow trout are found downstream of Glen Canyon (Fig. 3). Small 456 age- 0 cohorts in reaches III and IVa grew rapidly between January and July, and appeared to 457 recruit to the adult population in 2013 and 2014. Inferences regarding the presence of age-0 trout 458 in reach IVb were similar when all data was included compared to a subset of data which 459 excluded slow electrofishing and hoop net catches (only conducted in IVb) which potentially 460 increased the vulnerability of smaller fish. Ripe fish were commonly found in reaches III, IVa, 461 and IVb in winter and spring of 2013 and 2014, so the presence of age-0 fish at that time is likely 462 indicative of local reproduction rather than downstream dispersal of age-0 fish, especially given 463 their absence in reach II. Length-frequency distributions revealed the presence of a dominant 
464 465 466

cohort produced in 2011 in Glen Canyon, which determined the trajectory of abundance and the likely source of most immigrants to the LCR over the study period. This cohort was most apparent on the April 2012 trip as seen by the dominant 75-150 mm mode in reach I, and the dominant 100-175 mm mode in reaches II and III (Fig. 3).

\section{Abundance, Survival, and Recruiment Estimates from the Jolly-Seber Model}

Jolly-Seber models that assumed equal capture probability for fish recaptured within and across trips $\left(\mathrm{P}_{\mathrm{t}}\right.$, within $=$ across $)$ fit the data relatively poorly (as indicated by lower log likelihoods and higher estimates of overdispersion), and had much higher AIC values, compared to models that allowed these two types of capture probability to differ $\left(\mathrm{P}_{\mathrm{tb}}\right.$, within $\neq$ across , Table 3). The parameter for the effect of previous capture on a trip on later capture probabilities on the trip ( $\beta$ in eqn. 4 of Table S2) was positive for all reaches, indicating that within-trip capture probability was higher than across-trip capture probability. As across-trip capture probability is used to predict the abundance of unmarked fish, the lower across-trip capture probability under model $\mathrm{P}_{\mathrm{tb}}$ led to higher estimates of abundance and survival rate compared to model $\mathrm{P}_{\mathrm{t}}$. Differences in AIC between models that allowed the 90-day survival rate to vary $\left(\mathrm{S}_{\mathrm{t}}\right)$ or not vary $\left(\mathrm{S}_{\mathrm{o}}\right)$ among trip intervals were generally small, indicating limited to modest support for models that allowed survival to vary over time. Model fit was only marginally improved by the additional survival parameters of $\mathrm{S}_{\mathrm{t}}$ (except in reach III, Fig. S3) and differences in abundance and survival estimates among survival models were relatively small (Table 3). Given these results, and the good fit of model $\mathrm{P}_{\mathrm{tb}}-\mathrm{S}_{\mathrm{o}}$ to the data, we used model $\mathrm{P}_{\mathrm{tb}}-\mathrm{S}_{\mathrm{o}}$ for subsequent analyses.

Spatial and temporal differences in abundance indicate that very limited migration from the large source of trout upstream of IVa could lead to substantive increases in abundance of the much smaller population near the LCR. The averages of abundance estimates over the study period declined sharply and consistently between reach I and IVb with increasing distance from Glen Canyon Dam. Trout abundance in the robust design sections of reaches I and II were extremely high with peak values of approximately 25,000 (CV=0.19) and 15,000 (CV=0.15) fish/km, respectively (Fig. 4). In contrast, peak abundance in reaches just above (IVa) and below $(\mathrm{IVb})$ the LCR were approximately 2,000 $(\mathrm{CV}=0.08)$ and $800(\mathrm{CV}=0.12)$ fish/km, respectively. On average, the abundance in the robust design sections of reaches I-III declined by $50 \%$ during the period of study, while abundance increased by over $250 \%$ in reaches near the LCR. Total 
abundance over the entire study area was estimated to be approximately 1.5 million trout on the first trip (April 2012) and declined to less than 1,000,000 on the most recent trips (Fig. 5). Averaged across trips, more than $75 \%$ of the abundance in the study area was located in Glen Canyon and upper Marble Canyon and only $0.5 \%$ of the total abundance was located below the LCR.

Survival rate over a 90 day period averaged 0.76 across reaches. Survival rates in reaches I-IVa averaged 0.81 compared to 0.59 in reach IVb (Fig. 6). Average relative immigration rates (average number of immigrants per resident) were lowest in reach I and highest in IVb, with reaches in Marble Canyon showing intermediate values. The patterns in relative immigration and survival highlight that the rainbow trout population below the LCR is relatively transient, requiring high levels of recruitment for the population to increase over time given its low survival rate.

\section{Movement}

The vast majority of rainbow trout exhibited very limited movement based on differences between release and recapture locations. Of the 8,301 across-trip recaptures where release and recapture locations was known, the average movement distance was $0.45 \mathrm{~km}$ downstream, and $95 \%$ of recaptures moved no more than $2.6 \mathrm{~km}$ upstream and $5.2 \mathrm{~km}$ downstream. The average duration between release and recapture was 220 days. There were rare cases where fish moved longer distances. Restricting inferences to the 84 rainbow trout that moved more than $20 \mathrm{~km}$ $(1.0 \%$ of the total number of across-trip recaptures), approximately $70 \%$ moved in a downstream direction (Table S4). Only 11 trout marked in Glen Canyon were recaptured in reaches located downstream. Eight of these fish were marked as juveniles $(<150 \mathrm{~mm})$, two were released and recaptured as juveniles, and only one fish was large enough to spawn at the time of release ( >250 mm). Sixteen fish released downstream of the LCR or in Marble Canyon were recaptured in Glen Canyon, and 7 of these fish were released and recaptured at a size large enough to spawn.

There was strong evidence for episodic movement. Forty-three percent of the 84 trout that moved $>20 \mathrm{~km}$ were recaptured on our last sampling trip (September 2014, Table S4). Although we expect the frequency of long-distance recaptures to increase over time with the cumulative number of marks at large, and to vary by trip with capture probability, the very large fraction captured on the September 2014 trip is much greater than would occur due to these 
526 factors. Eight of the 11 trout (73\%) that emigrated from Glen Canyon came from the November

5272011 marking cohort, even though that cohort represented only $21 \%$ of all fish marked in Glen

528 Canyon over the study period. Thus, a much higher fraction of fish from the very large 2011

529 cohort moved relative to smaller cohorts produced in 2012 and 2013.

530 The Cauchy function generally provided a good representation of the distribution of weighted movement distances (Fig. 7). The majority of reaches and trip intervals showed similar movement distance distributions that were generally narrow and centered at $0 \mathrm{~km}$ (Fig. 8). Small movement distances were most frequent in reach I and longer movements were most frequent in reach $\mathrm{IVb}$, and downstream rather than upstream movement occurred more often in IVb. Across trip intervals, movement was lowest in winter (Jan-Apr) when the majority of spawning occurs in Glen Canyon (Korman et al. 2011), and highest in summer (Jul-Sep) and fall (Sep-Jan) when turbidity is higher in reaches II-IVb (Fig. S1c).

The proportion of tagged trout that remained in robust design sections (central $2 \mathrm{~km}$ of reaches I-III, all of reaches IVa and IVb) as determined by Cauchy movement distributions and the spatial distribution of tagged trout released among sites, varied with the length of time since tagging and among reaches. On average, $85 \%$ of trout tagged in robust design sections remained in this section after $24 \mathrm{~h}$ (Table 4). One trip after release, the proportion remaining in the robust design section declined to $77 \%$. Two or more trips after release, the average residency proportion declined to $69 \%$. These observations suggest a surprising initial movement due to the disturbance of sampling and release, and then a modest dispersal over longer time periods. Note that in the Jolly-Seber model, fractional losses due to movement among trip intervals for any marked cohort are based on the incremental differences in residency on successive trips, which were typically relatively small. The average incremental loss due to movement between the first and second trip after release was $8 \%(77 \%-69 \%)$. The proportion of tagged fish that stayed within the robust design sections was always highest in reach I and almost always lowest in reach IVb due to differences in movement distributions (Fig. 8).

The number of rainbow trout recaptured in reaches other than the ones where they were marked in was very low relative to the total number of recaptures. Based on all sampling efforts, including fall Glen Canyon trips, only 158 of 8,166 recaptures (1.9\%) were from reaches other

555 than the one they were released in (Table 5a). Restricting the analysis to marked trout released 556 and recaptured on downstream trips only (Table 5b) resulted in a large reduction in recaptures 
557 for fish released upstream of Lees Ferry, though the conclusion of limited across-reach

558 movement still holds. There were only 142 across-reach recaptures in this restricted data set used

559 by the across-reach movement model, with more than half resulting from exchange between

560 reaches $\mathrm{IVa}$ and $\mathrm{IVb}$, which are relatively close together. With respect to predicting immigration

561 to IVa and IVb from upstream sources, there were only 33 cases where marked trout were

562 released in reaches I-III and recaptured in reaches near the LCR (Table 5b). The average time

563 between release and recapture for marked trout released in reaches I, II and III and recaptured in

564 IVa or IVb was $408(\mathrm{CV}=1.1, \mathrm{n}=2), 302(\mathrm{CV}=0.55, \mathrm{n}=14)$, and $347(\mathrm{CV}=0.66, \mathrm{n}=17)$ days,

565 respectively.

566 Estimated across-reach movement percentages indicated very limited movement between

567 most reaches. An average of only $1 \%$ of trout marked in reaches I, II, or III were estimated to

568 move to reaches other than the ones they were released in (Table 5c). There was more exchange

569 between reaches IVa and IVb due to their close proximity, and estimated movement proportions

570 indicated a greater tendency for trout to move downstream from IVa to IVb $(7.8 \%)$ compared to

571 moving upstream (1.7\%). Movement proportions from reaches I-III to reaches near the LCR

572 (rightmost column of Table 5c) suggest very limited movement from Glen Canyon to the LCR,

573 and a higher probability of moving from locations in Marble Canyon to the LCR with decreasing 574 distance.

$575 \quad$ Figure 9 provides a graphical description of how abundance and movement estimates for 576 upstream reaches are combined to predict immigration to reaches near the LCR. Trip-specific 577 estimates of abundance for each river km upstream of IVa or IVb (Fig. 9a) are multiplied by the 578 predicted proportion of those fish destined to move to IVa or IVb based on the movement 579 distance distribution that is assumed to represent each 1-km section (Fig. 9 b). Those movement 580 distributions are narrow, indicating that only a small proportion of fish make large downstream movements. The probability of longer movement distances to IVb is lowest for reach I and

582 highest for 4A. Uncertainty in the spatial trend in upstream abundance (Fig. 9a) and movement 583 distance distributions (example for reach II provided in Fig. 9c) are incorporated into the 584 prediction of immigration to IVa and IVb from upstream sources (' $U$ ' columns in Fig. 9d). 585 Predicted and estimated recruitment to reaches near the LCR were in close agreement. 586 The Jolly-Seber model estimated that 16,200 rainbow trout recruited to reaches IVa and IVb over 587 the study period ('W' bars in Fig. 9d). The mean of the posterior distribution of the predicted 
588 immigration to these reaches from upstream sources, determined by the across-reach movement 589 model, was 17,400 trout ('U' bars in Fig. 9d). Reach-specific results were also in close 590 agreement. Locations closer to reaches near the LCR (lower Marble Canyon) made larger 591 contributions to immigration relative to more distant sources (Glen Canyon and upper and 592 middle Marble Canyon), even though abundance at the more distant source locations was much 593 higher. In reach IVa, the vast majority of immigration came from the section represented by 594 reach III (Fig. 9a and d). The majority of immigration to reach IVb was from approximately 595 equal contributions from sections represented by III and IVa. Direct contributions from Glen 596 Canyon to reaches near the LCR were very limited between the April 2012 - September 2014 period that was modelled owing to the very narrow movement distribution from reach I (Fig. 9b).

\section{Discussion}

600

601

602

603

604

605

606

607

608

609

610

611

612

613

614

615

616

617

The main goal of our study was to determine whether the abundance of non-native rainbow trout in a critical reach for humpback chub at the confluence of the LCR is supported by local reproduction or downstream dispersal. Trout abundance declined in Glen Canyon and upper and middle Marble Canyon over the study period, while the population grew in reaches near the LCR. As there was little evidence for variation in survival rates over time or substantive local recruitment in reaches near the LCR, this pattern can only be explained by reduced recruitment in upstream reaches combined with movement from upstream to downstream reaches. The extent of long-range movement was limited with only $1 \%$ of over 8,000 recaptures making movements greater than $20 \mathrm{~km}$. Our analysis showed that this small relative rate of longdistance dispersal from upstream reaches with very high densities was sufficient to increase trout density near the LCR, where absolute abundance is much lower. However, not all fish that dispersed to the LCR confluence area originated in Glen Canyon. Length-frequency data indicated that some juvenile trout were produced in Marble Canyon, and these fish contribute to upstream source populations which drive trout abundance near the LCR. Our study showed that high and steady flows like those in 2011, which produce large numbers of juvenile trout in Glen Canyon (Avery et al. 2015) and increase catch rates in the tailwater fishery (Rogowski et al. 2015), unfortunately also lead to higher trout abundance near the LCR. Quantifying the trade-off between the Glen Canyon trout fishery and the status of humpback chub will require continued 
monitoring of both species at the LCR to better define the relationship between rainbow trout abundance and the productivity of the humpback chub population.

Recovery of tagged rainbow trout from out study indicated very limited outmigration from Glen to Marble Canyon. This presents a paradox, as abundance of trout $<175 \mathrm{~mm}$ at the start of the study in reaches II and III was high, yet there was no evidence of substantive local reproduction in these reaches at this time. Yard et al. (this issue) demonstrate that lengthfrequency distributions in these reaches on the first downstream trip (April 2012) are well predicted by advancing the observed length frequency in Glen Canyon at the start of the study (November 2011) using growth rates estimated from Marble Canyon. Results from this size frequency analysis, in combination with the following evidence, indicate that the very abundant population of trout $<175 \mathrm{~mm}$ in upper and middle Marble Canyon on the April 2012 trip very likely originated from the large cohort produced in Glen Canyon in 2011: 1) Trout $<175 \mathrm{~mm}$ in reaches II and III in April 2012 were too small to originate from the 2010 cohort from Glen Canyon given observed growth rates (Yard et al. this issue); 2) we captured and tagged over 1,000 age- 0 rainbow trout in the first $6 \mathrm{~km}$ downstream of Lees Ferry in one night on our first marking trip in November 2011, indicating that some of the 2011 cohort had already emigrated from Glen Canyon to upper Marble Canyon by that time (successful reproduction in this $6 \mathrm{~km}$ section located immediately below the Paria River is unlikely owing to highly embedded substrate, thus age-0 fish captured in this reach very likely originated from Glen Canyon); and 3) length-frequencies indicated that age-0 fish were extremely rare in reach II throughout the study, thus it is unlikely that substantive local reproduction would have occurred prior to the first downstream trip in April 2012. While some age-0 trout were present in length-frequencies for reach III, the proportion was small in 2013 and increased in 2014, suggesting limited local reproduction in 2012. The majority of outmigration of the 2011 cohort from Glen Canyon therefore likely occurred prior to our first downstream trip in April 2012. This finding is consistent with other studies which show significant downstream movement for salmonid fry and parr (LeCren 1973; Mortensen 1977a; Mills 1969; Randall 1982).

Patterns of movement documented in this study were variable over time and likely driven by a combination of trout density, trout condition, and turbidity. Downstream recaptures of marked trout released in Glen Canyon after the November 2011 trip were very rare even though they represented more than $75 \%$ of all fish marked in Glen Canyon. Thus, the relative rate of 
649

650

651

652

653

654

655

656

657

658

659

660

661

662

663

664

665

666

667

668

669

670

671

672

673

674

675

676

677

678

679

emigration from Glen Canyon was higher following the production of the very large 2011 cohort. This observation is consistent with studies that have documented increasing downstream movement rates for juveniles rearing under higher densities and when less food is available (Hansen and Closs 2009; Olsson and Greenberg 2004; Olsson et al. 2006; Morita et al. 2000; Wysujack et al. 2008). Dispersal rates of trout in reach IVb, which were predominantly larger fish, was greatest in summer and fall intervals in 2013 and 2014 when high levels of turbidity reduced foraging efficiency and led to poor fish condition (Fig. S1c, Yard et al. this issue). This observation is consistent with studies that show lower condition in mobile individuals relative to residents (Naslund et al. 1993; Gowan and Fausch 1996; Hilderbrand and Kershner 2004). Movement of rainbow trout in lower Marble Canyon inferred from this study was more restricted compared to estimates from the 2003-2006 mechanical removal study (Coggins 2008). Ninety five percent (95\%) of recaptures of trout released in reach III, IVa, or IVb $(n=4023)$ moved less than $2.2 \mathrm{~km}$ upstream and $5.3 \mathrm{~km}$ downstream. In comparison, 95\% of movement distances over a similar area between 2003 and 2006 were between $6.4 \mathrm{~km}$ upstream and $21.6 \mathrm{~km}$ downstream $(n=1564)$. We speculate that differences in movement rates between studies are related to variation in the energetic condition of trout across the two periods.

Differences in survival rates of rainbow trout in reaches above and below the LCR confluence highlight the transient nature of the population below the confluence, and the importance of immigration in supporting its abundance. Our survival rate estimates for reaches IIVa were within or close to the range reported for rainbow trout from studies which measured annual growth (Froser and Pauly 2014), from which survival could be calculated (Jensen 1996, grey dashed line in Fig. 6). The 90-day survival rate in the reach below the LCR was $27 \%$ lower than in reach IVa that is located only $5 \mathrm{~km}$ upstream. In the absence of recruitment (immigration or local reproduction), the survival rate for reach $\mathrm{IVb}$ predicts that the population would decline to $12 \%$ of its abundance after one year. It seems likely that prolonged periods of turbidity (Fig. S1c) that lead to substantive reductions in fish condition (see Fig. 4 of Yard et al., this issue) is the cause of both lower survival and greater movement rates in reach IVb.

Our improved understanding of the population dynamics of rainbow trout below Glen Canyon Dam has a number of implications with regards to the control of this non-native species. First, as high trout densities likely increase emigration rate (e.g., Morita et al. 2000), reducing densities in Glen Canyon is a logical way to limit trout abundance at the LCR. However, 
680

681

682

683

684

685

686

687

688

689

690

691

692

693

694

695

696

697

698

699

700

701

702

703

704

705

706

707

708

709

710

proposed mechanical removal of trout in Glen Canyon (BOR 2011) will require an extremely large effort and would encounter strong opposition from sport fishing interests. Approximately 10 days of effort are needed to electrofish the entire shoreline of Glen Canyon. Given a capture probability of 0.02 in Glen Canyon estimated in this study, a 50\% reduction in the population would require 34 passes of effort, equivalent to electrofishing almost every night for a year. Trout abundance in Glen Canyon could also be reduced by increasing angler harvest in the sport fishery, but this may be difficult to achieve as the most recent creel assessment indicates that less than $5 \%$ of the catch is harvested (Rogowski et al. 2015.), and anglers may be unwilling to abandon catch-and-release. Mechanical removal in the first $12 \mathrm{~km}$ of upper Marble Canyon has been proposed (BOR 2011) to intercept emigrants from Glen Canyon while not affecting the sport fishery. Our study indicates that the timing of emigration from Glen Canyon is episodic, making it unlikely that removal efforts just below Lees Ferry would intercept a large fraction of migrating fish. Second, using flow fluctuations to limit survival rates of recently emerged trout in Glen Canyon (BOR 2011) is a logical alternative as our study indicates that the majority of emigrants from Glen Canyon left within their first year, and possibly within 6 months from emergence. Our results also indicate that the fraction of trout emigrating from Glen Canyon was higher in a year when a large cohort was produced, thus to minimize impacts to the tailwater fishery, flow-control may only be needed in years where large cohorts are anticipated, such as in equalization years (Avery et al. 2015) or following controlled floods in spring (Korman et al. 2011). Third, it appears that mechanical removal efforts near the LCR will have to be part of any trout control strategy to account for the large population of trout in upper and middle Marble Canyon that may be present but will likely not be directly impacted by flow fluctuations. However, mechanical removal near the LCR is no panacea because it will not lead to sustained periods of low abundance when immigration into the removal area is high (Coggins et al. 2011). We documented an increase in local reproduction in middle and lower Marble Canyon over the study period. We suspect this trend was caused by increased abundance of adult trout as the dominant 2011 cohort aged, combined with relatively clear water and less embedded substrate resulting from two controlled floods and an equalization flow over the study period. High flow releases from Glen Canyon Dam are intended to rebuild sand bars in Grand Canyon (controlled floods) or equalize storage volumes in Lake Powell and Mead (equalization flows). These high flows rework the bed by scouring and redepositing finer sediments at higher 
711 elevations (Schmidt et al. 1999), resulting in clearer water and less embedded substrate which

712 could contribute to increases in reproductive potential and success. These high flow management 713 strategies may be inadvertently extending the trout-producing tailwater further downstream.

The estimates of rainbow trout densities near the LCR from this study are considerably 715 higher than those determined during the 2003-2006 mechanical removal effort (Coggins et al.

716

717

718

719

720

721

722

723

724

725

726

727

728

729

730

731

732

733

734

735

736

737

738

739

740

741 2011; Coggins 2008). The most recent (and highest) abundance estimates presented here for reaches IVa and IVb are 2.5- and 4.8-fold greater than estimates for similar areas determined at the start of the removal effort (January 2003), respectively. Furthermore, the most recent trout density estimate in reach III, which represents the density of the dominant source of immigrants to the LCR, is 3.8-fold higher than the density from a similar area sampled at the start of the mechanical removal study. These comparisons suggest that negative effects of rainbow trout on humpback chub are now greater than they were at the start of the 2003-2006 removal effort.

Our conclusion that trout abundance at the LCR is driven by dispersal from upstream sources depends in part on estimates of abundance in each reach, which in turn depend on estimates of across-trip capture probability. We were surprised that capture probability for fish previously captured within a trip was substantively higher than for fish that had been at large since the last trip (typically 3 months or longer). We had assumed that the process of capturing trout by electrofishing would make them less vulnerable to later capture shortly after release (Peterson et al. 2004). These patterns in capture probability could be driven by heterogeneity in capture probability among individuals, effects from sampling (capture effects and release location), or temporary immigration (Williams et al. 2001). With respect to heterogeneity in capture probability, fish using nearshore habitats in shallower water would be more vulnerable to capture than fish using habitats found further from shore and in deeper water where electrofishing is less effective (Bayley and Austen 2002). If such habitat use holds over secondary sampling periods within a trip (i.e., a few days to a week), fish captured on the early passes would more likely be from the nearshore group and return to these habitats after release, making them more likely to be captured on subsequent passes of the trip relative to fish using offshore habitats. Exchange of marked fish between offshore and nearshore groups between trip intervals would lead to lower across-trip capture probability compared to within-trip capture probability. Alternatively, the process of capture, handling, and release, could result in a shortterm response of fish using slower and shallower nearshore habitats (Mesa and Schreck 1989) 
742

743

744

745

746

747

748

749

750

751

752

753

754

755

756

757

758

759

760

761

762

763

764

765

766

767

768

769

770

771

772

where electrofishing is more effective. Higher rates of temporary immigration for fish released on previous trips relative to those released on previous nights on the same trip could also explain lower across-trip capture probabilities (Kendall et al. 1997). However, based on examination of locations for 230 individual trout recaptured on more than one trip, there was less evidence for temporary immigration (fish moving in and out of robust design sections between trips) than for permanent movement (results not shown for brevity). Thus, heterogeneous capture probability among individuals or sampling effects appear to be the more likely mechanisms explaining lower across-trip capture probability.

In spite of a large sampling effort, our understanding of the temporal dynamics controlling downstream migration is far from complete. There was very good agreement between within-reach estimates of immigration to reaches near the LCR from the Jolly-Seber model, and independently-determined values based on abundance and movement rates from upstream sources. However, the limited number of recaptures from upstream reaches to reaches near the LCR (33) precludes a quantitative evaluation of potential lags, temporal variation, and environmental-, fish size-, and fish condition-effects on movement. We hope to improve our understanding of movement dynamics when data from the remaining two years of this study are available. Our results to date indicate that local recruitment within LCR reaches is very limited, and is likely not an important determinant of trout abundance in this critical area. However, we cannot rule out the importance of local reproduction in the long term, especially considering that trout produced in Marble Canyon contribute to the population at the LCR. The contribution from local reproduction within Marble Canyon could be substantive during periods which promote growth and reproductive success of trout in Marble Canyon, especially when immigration from upstream sources is limited. This combination of events might occur three or more years after the production of a large cohort in Glen Canyon, especially under a policy of high flow releases which improve spawning conditions in Marble Canyon.

We did not evaluate the effects of fish size on capture probability or survival in this paper. The size distributions for all reaches except reach I were relatively narrow and few small fish were available to PIT-tag, thus parameters from a size-stratified model would be challenging to estimate for reaches II-IVb. We have developed a fish size- and spatially-stratified Jolly-Seber model for Glen Canyon (Korman and Yard, unpublished data) and will present results from that effort in a future manuscript. This model uses releases and recaptures from both downstream 
773 trips, and fall Glen Canyon trips which cover the entire shoreline of this reach. The model 774 predicts lower survival rates for smaller size classes $(75-125 \mathrm{~mm}, 125-175 \mathrm{~mm})$ and declining

775

776

777

778

779

780

781

782

783

784

785

786

787

788

789

790

791

792

793

794

795

796

797

798

799

800

801

802 capture probability with increasing fish size. Although the size-stratified model provides more detail about population dynamics in Glen Canyon, the scale and temporal trend in the sum of abundance across size classes are similar to what is presented here. The average survival rate across size classes is also similar to the survival estimates presented here, and both models indicate limited support for temporal variation in survival rates over the study period. Thus, the use of a consistent modelling framework across reaches in this analysis, that could not make full use of available data for Glen Canyon or account for fish size effects, does not appear to have produced a biased assessment of population dynamics in reach I where the size distribution is widest.

Our study provides some unique methodological advances and insights about the feasibility of understanding the dynamics of fish populations in a large river. The sampling design and analytic framework allowed us to separate movement- and mortality-related losses from the population, which is rare in open population models. The method used for adjusting movement distributions to account for the effects of the sampling design on the probability of observing various movement distances seems widely applicable. The use of a negative binomial distribution to fit the Jolly-Seber or other mark-recapture models provides a direct way of estimating overdispersion and the correct variance without the need for a post-hoc variance adjustment. The approach to account for overdispersion based on the multinomial likelihood used in most mark-recapture analyses is vulnerable to small sample size effects in the computation of the $\chi^{2}$ used to inflate the variance (c-hat), and the variance inflation factor can be difficult to estimate if parameters in the global model are confounded. Finally, our effort has demonstrated that it is possible to get a reliable picture of the demographics of a fish population over a large study area in a logistically-challenging, large-river environment. However, such studies can only be implemented in systems with sufficient resources and a pressing need to address management uncertainties. Smaller efforts, such as spatially-limited catch-per-effort sampling, are more feasible but may have little utility to address management questions relative to the large scale mark-recapture program described here. 


\section{Acknowledgements}

804

805

806

807

808

809

810

811

812

813

814

815

816

818 817 which improved the quality of the manuscript.

US Geological Survey, Grand Canyon Monitoring and Research Center provided the logistical support and funded this study under the Grant and Cooperative Agreements No. G11AC20423. We are extremely grateful to all of the fishery technicians that have worked on this project. We would like to thank Evan Anderson, Chelsie Arndt, Peter Atkinson, Margeaux Bestard, Erica Byerly, Tanner Carothers, Mariah Giardina, Jake Hall, Ellie Johnson, and many volunteers. We also express our thanks to the two logistical contractors Humphrey Summit Support and St. Jude Enterprises that provided the highly experienced and dedicated boat operators, Drew Andersen, Kirk Burnette, Brian Dierker, Carolyn Forenza, Dennis Harris, Jason Moore, Brett Stark, and Jamie Townsend. Additional thanks goes to the GCMRC staff that also assisted on this project that included Luke Avery, Glenn Bennett, Adam Coop, Kim Dibble,

814 Carol Fritzinger, Tom Gushue, Eric Kortenhoeven, Ted Melis, Anya Metcalfe, Bill Persons, 815 Connor Phillips, Tom Quigley, Ben Vaage, Scott VanderKooi, and Dave Ward. We thank Kevin 816 Bestgen, an anonymous reviewer, and Keith Tierney for providing many helpful suggestions 


\section{References}

820

821

822

823

824

825

826

Bayley, P.B., and Austen, D.J. 2002. Capture efficiency of a boat electrofisher. Trans. Am. Fish.

Avery, L.A., Korman, J., and Persons, W.R. 2015. Effects of increased discharge on rainbow trout spawning and age-0 recruitment in the Colorado at Lees Ferry, AZ. Nor. Am. J. Fish. Manage. 35: 671-680.

827

828

829 Soc. 121:435-451.

Bureau of Reclamation. 2011. Biological assessment for non-native fish control downstream from Glen Canyon Dam. Salt Lake City, UT. http://www.riversimulator.org/Resources/USBR/LTEMP/BAofNNFCea2011.pdf accessed November 17, 2014.

835

Bureau of Reclamation. 1995. Final Environmental Impact Statement: Operation of Glen Canyon Dam, Colorado River Storage Project, Arizona. Salt Lake City, UT.

838

Burnham, K. P., and Anderson, D. R. 2002. Model selection and multimodel inference, 2nd edition. Springer-Verlag, New York.

Coggins, L.G. Jr., and Walters, C.J. 2009. Abundance trends and status of the Little Colorado River population of humpback chub: an update considering data from 1989-2008. U.S. Geological Survey, Open-File Report 2009-1075. Available: pubs.usgs.gov/of/2009/1075/. (March 2010). 
848

849

850

851

852

853

854

855

856

857

858

859

860

861

862

863

864

865

866

867

868

869

870

871

872

873

874

875

876

877

878

Coggins, L.G., Jr. 2008. Active adaptive management for native fish conservation in the Grand Canyon: implementation and evaluation. Doctoral dissertation. University of Florida, Gainesville, FL.

Cross, W.F., Baxter, C.V., Donner, K.C., Rosi-Marshall, E.J., Kennedy, T.A., Hall, R.O., Kelly, H.A.W., and Rogers, R.S. 2011. Ecosystem ecology meets adaptive management: food web response to a controlled flood on the Colorado River, Glen Canyon. Ecol. App. 21: 2016-2033.

Fournier, D.A., H.J. Skaug, Ancheta, J., Ianelli, J., Magnusson, A., Maunder, M.N., Nielsen, A., and Sibert, J. 2011. AD Model Builder: using automatic differentiation for statistical inference of highly parameterized complex nonlinear models. Optimization Methods \& Software. Available from http://admb-project.org/ [accessed 17 February 2012].

Froser, R. and Pauly, D. (Editors). 2014. FishBase. Word Wide Web electronic publication. www.fishbase.org. Accessed August 2014.

Gelman, A., Carlin, J.B., Stern, H.S., and Rubin, D.B. 2004. Bayesian data analysis, $2^{\text {nd }}$ Edition. Chapman \& Hall/CRC, Boca Raton, FL. 668 p.

Gloss, S.P., and Coggins, L.G. Jr. 2005. Fishes of Grand Canyon. P. 33-56. In The state of the Colorado River ecosystem in Grand Canyon: a report of the Grand Canyon Monitoring and Research Center. Edited by S.P. Gloss, J.E. Lovich, and T.S. Melis. Flagstaff, AZ. http://pubs.usgs.gov/circ/1282/. [accessed 14 February 2011].

Gowan, C., and Fausch, K.D. 1996. Mobile brook trout in two high-elevation Colorado streams: reevaluating the concept of restricted movement. Can. J. Fish. Aquat. Sci. 53:1370-1381.

Hansen, E.A., and Closs, G.P. 2009. Long-term growth and movement in relation to food supply and social status in a stream fish. Behav. Ecol. 20: 616-623. 
879 880 881 882 883 884 885 886 887 888 889 890 891 892

893 894 895 896 897 898 899 900 901 902 903 904 905 906 907 908

Hilderbrand, R.H., and Kershner, J.L. 2004. Are there differences in growth and condition between mobile and resident trout? Trans. Am. Fish. Soc. 133:1042-1046.

Jensen, A.L. 1996. Beverton and Holt life history invariants result from optimal trade-off of reproduction and survival. Can. J. Fish. Aquat. Sci. 53: 820-822.

Kendall, W.L., Nichols, J.D., and Hines, J.E. 1997. Estimating temporary emigratin using capture-recapture data with Pollock's robust design. Ecology 78:563-578.

Korman, J., Martell, S.J.D., Walters, C.J., Makinster, A.S., Coggins, L.G., Yard, M.D., and Persons, W.R. 2012. Estimating recruitment dynamics and movement of rainbow trout (Oncorhynchus mykiss) in the Colorado River in Grand Canyon using an integrated assessment model. Can. J. Fish. Aquat. Sci. 69: 1827-1849.

Korman, J., Kaplinski, M., and Melis, T.S. 2011. Effects of fluctuation flows and a controlled flood on incubation success and early survival rates and growth of age- 0 rainbow trout in a large regulated river. Trans. Am. Fish. Soc. 140: 487-505.

LeCren, E. D. 1973. The population dynamics of young trout (SaImo trutta) in relation to density and territorial behaviour. Rapp. P.-V. Reun. Cons. Perm. Int. Explor. Mer 164: 241 -246.

Makinster, A.S., Persons, W.R., Avery, L.A., and Bunch, A.J. 2010. Colorado River fish monitoring in Grand Canyon Arizona - 2009 to 2009 Summary. USGS open-file report 2010-1246. Available from http://pubs.usgs.gov/of/2010/1246. [accessed 17 February 2012].

Marsh, P.C. and Douglas, M.E. 1997. Predation by introduced fishes on endangered humpback chub and other native species in the Little Colorado River, Arizona. Trans. Am. Fish. Soc 126: 343-346. 
McKinney, T., Speas, D.W., Rogers, R.S., and Persons, W.R. 2001. Rainbow trout in a regulated river below Glen Canyon Dam, Arizona, following increased minimum flows and reduced discharge variability. Nor. Am. J. Fish. Manage. 21: 216-222.

Melis, T.S., Walters, C.J., and Korman, J. In Press. Surprise and opportunity for learning in Grand Canyon: the Glen Canyon Dam Adaptive Management program. Ecol. Soc.

Mesa, M.G., and Schreck, C.B. 1989. Electrofishing mark-recapture and depletion methodologies evoke behavioural and physiological changes in Cutthroat trout. Transactions of the American Fisheries Society 118:644-658.

Mills, D. H. 1969. The survival of hatchery reared salmon fry in some Scottish streams. Dep. Agric. Fish. Scot. Fresh. Salmon Fish. Res. Rep. No. 39: 12 p.

Morita, K., Yamamoto, S., and Hoshino, H. 2000. Extreme life history change in white-spotted charge (Salvelinus leucomaenis) after damming. Can. J. Fish. Aquat. Sci. 57:1300-1306.

Mortensen, E. 1 977. The population dynamics of young trout (Salmot trutta L.) in a Danish brook. J. Fish Biol. 10: 23-33.

Muneepeerakul, R., Bertuzzo, E., Lynch, H.J., Fagan, W.F., Rinaldo, A., and Rodriguez-Iturbe, I. 2008. Neutral metacommunity models predict fish diversity in Mississippi-Missouri basin. Nature 453: 220-222.

Naslund, I., G. Milbrink, O. Eriksson, and Holmgren, S.1993. Importance of habitat productivity differences, competition, and predation for the migratory behaviour of Arctic charr. Oikos 66:538-546.

Olden, J. D., N. L. Poff, and Bestgen, K. R. 2006. Life history strategies predict fish invasions and extirpations in the Colorado River basin. Ecol. Monogr. 76: 25-40. 
940

945

946

947

948

949

950

951

952

953

954

955

956

957

958

959

960

961

962

963

964

965

966

967

968

969

970

Olsson, I.C., and Greenberg, L.A. 2004. Partial migration in a landlocked brown trout population. J. Fish Biol. 65: 106-121.

Olsson, I.C., Greenberg, L.A., Bergman, E., and Wysujack, K. 2006. Environmentally induced migration: the importance of food. Ecol. Lett. 9: 645-651.

Peterson, J.T., R.F. Thurow, and Guzevich, J.W. 2004. An evaluation of multipass electrofishing for estimating the abundance of stream-dwelling salmonids. Transactions of the American Fisheries Society 133:462-475.

Randall, R.G. 1982. Emergence, population densities, and growth of salmon and trout fry in two New Brunswick streams. Can. J. Zool. 68: 2239 -2244.

Rogowski, D.L., Winters, L.K., Wolters, P.N., and Manuell, K.M. 2015. Status of the Lees Ferry rainbow trout fisher 2014 annual report. Reported prepared by the Arizona Game and Fish Department for the Grand Canyon Monitoring and Research Center. 41 pp.

Sabo, J. T., Sinha, T., Bowling, L.C., Schoups, G.H.W., Wallender, W.W., Campana, M.E., Cherkauer, K.A., Fuller, P.L., Graf, W.L., Hopmans, J.W., Kominoski, J.S., Taylor, C., Trimble, S.W., Webb, R.H., Wohl, E.E., and MacDonald, G.M. 2010. Reclaiming freshwater sustainability in the Cadillac Desert. PNAS. 107: 21263-21270.

Schmidt, J.C., Andrews, E.D., Wegner, D.L., Patten, D.T., Marzolf, G.R., and Moody, T.O. 1999. Origins of the 1996 controlled flood in Grand Canyon. In The controlled flood in Grand Canyon. Edited by R.H. Webb, J.C. Schmidt, G.R. Marzolf, and R.A. Valdez. Washington, D.C., American Geophysical Union, Geo-physical Monograph Series, 110, pp $23-36$.

Strayer, D. L. 2010. Alien species in fresh waters: ecological effects, interactions with other stressors, and prospects for the future. Freshwater Biol. 55: 152-174. 
971 Sturtz, S., Legges U., and Gelman A. 2005. R2WinBGS: a package for running WinBUGS from 972 R. J. Stat. Softw. 3: 1-16.

973

974 Venebles, W.N., and Ripley, B.D. 2002. Modern applied statistics with S. Fourth edition. 975 Springer.

976

977 Walters, C., J. Korman, L. E. Stevens, and Gold, B. 2000. Ecosystem modeling for evaluation of 978 adaptive management policies in the Grand Canyon. Conservation Ecology 4(2): 1.

979

980 981

Williams, B.K., Nichols, J.D., and Conroy, M.J.. 2001. Analysis and management of animal populations. Academic Press. 817 pp.

982

983

984

985

Wysujack, K., Greenber, L.A., Bergman, E., and Olsson, I.C. 2008. The role of environment in partial migration: food availability affects the adoption of a migratory tactic in brown trout

Valdez, R.A., and Carothers, S.W. 1998. The aqatic ecosystem of the Colorado River in Grand Canyon. Report prepared for Bureau of Reclamation by SWCA Inc., Flagstaff, AZ.

989

990 Salmo trutta. Ecol. Fresh. Fish 18: 52-59.

Yard, M.D. Coggins, L.G., Baxter, C.V., Bennett, G.E., and Korman, J. 2011. Trout piscivory in the Colorado River, Grand Canyon: effects of turbidity, temperature, and fish prey availability. Trans. Am. Fish. Soc. 140:471-486. 
Table 1. Total catch of rainbow trout by trip and number PIT-tagged by trip and reach (a), and number of across-trip PIT-tag recaptures by release trip and release reach (b). Cells in grey denote catch and number of trout tagged during fall Glen Canyon (GLC) trips. The column labeled GLC excl. I is the number of releases (a) or recaptures (b) in GLC excluding those released in reach I which is shown in the column to the right.

a)

\begin{tabular}{|c|c|c|c|c|c|c|c|}
\hline \multirow[b]{2}{*}{ Trip } & \multirow{2}{*}{$\begin{array}{c}\text { Total Catch } \\
\text { All Reaches } \\
\text { GLC-IVb } \\
\end{array}$} & \multicolumn{6}{|c|}{ PIT Tag Releases By Reach } \\
\hline & & excl. I & I & II & III & IVa & IVb \\
\hline Nov-11 & 16,440 & 8,703 & 2,782 & & & & \\
\hline Apr-12 & 11,775 & & 609 & 552 & 549 & 317 & 119 \\
\hline Jul-12 & 11,641 & & 768 & 795 & 848 & 339 & 197 \\
\hline Sep-12 & 17,897 & & 625 & 788 & 842 & 305 & 229 \\
\hline Oct-12 & 22,381 & 4,101 & 987 & & & & \\
\hline Dec-12 & 12,490 & 3,431 & 823 & & & & \\
\hline Jan-13 & 12,167 & & 728 & 776 & 987 & 347 & 336 \\
\hline Apr-13 & 9,765 & & 870 & 1,010 & 879 & 367 & 135 \\
\hline Jul-13 & 8,437 & & 815 & 828 & 882 & 428 & 279 \\
\hline Sep-13 & 13,787 & & 1,122 & 1,068 & 741 & 478 & 351 \\
\hline Oct-13 & 12,512 & 4,959 & 879 & & & & \\
\hline Dec-13 & 8,175 & 4,467 & 1,069 & & & & \\
\hline Jan-14 & 8,742 & & 949 & 1,209 & 1,198 & 554 & 398 \\
\hline Apr-14 & 7,109 & & 1,064 & 1,147 & 1,155 & 387 & 195 \\
\hline Jul-14 & 6,585 & & 1,089 & 1,162 & 933 & 428 & 390 \\
\hline Sep-14 & 13,156 & & 1,205 & 1,395 & 1,155 & 681 & 456 \\
\hline Total & 193,059 & 25,661 & 16,384 & 10,730 & 10,169 & 4,631 & 3,085 \\
\hline
\end{tabular}


Table 1. Con't.

b)

\begin{tabular}{|c|c|c|c|c|c|c|}
\hline \multirow[b]{2}{*}{ Trip } & \multicolumn{6}{|c|}{ PIT Tag Recaptures By Reach } \\
\hline & excl. I & $\mathbf{I}$ & II & III & IVa & IVb \\
\hline Nov-11 & 113 & 108 & & & & \\
\hline Apr-12 & & 87 & 144 & 206 & 149 & 42 \\
\hline Jul-12 & & 114 & 219 & 315 & 137 & 60 \\
\hline Sep-12 & & 73 & 193 & 211 & 124 & 60 \\
\hline Oct-12 & 249 & 95 & & & & \\
\hline Dec-12 & 61 & 112 & & & & \\
\hline Jan-13 & & 113 & 201 & 202 & 132 & 66 \\
\hline Apr-13 & & 119 & 255 & 228 & 133 & 43 \\
\hline Jul-13 & & 133 & 200 & 234 & 135 & 59 \\
\hline Sep-13 & & 90 & 178 & 128 & 126 & 41 \\
\hline Oct-13 & 326 & 103 & & & & \\
\hline Dec-13 & 13 & 120 & & & & \\
\hline Jan-14 & & 94 & 244 & 214 & 119 & 94 \\
\hline Apr-14 & & 63 & 187 & 215 & 125 & 48 \\
\hline Jul-14 & & 53 & 220 & 160 & 93 & 52 \\
\hline Sep-14 & & & & & & \\
\hline Total & 762 & 1,477 & 2,041 & 2,113 & 1,273 & 565 \\
\hline
\end{tabular}


Table 2. Summary of results from holding experiments used to quantify PIT-tag loss resulting from tag shedding and mortality due to capture and handling based on 24-hour holding experiments. Cells in grey denote statistics from Glen Canyon marking trips that are not used in the Jolly-Seber model.

\begin{tabular}{cccc}
\hline Trip & $\begin{array}{c}\text { \# of } \\
\text { Experiments }\end{array}$ & $\begin{array}{c}\text { \# of Trout } \\
\text { Held }\end{array}$ & $\begin{array}{c}\text { Tag } \\
\text { Loss }\end{array}$ \\
\hline Nov-11 & 3 & 602 & $1.3 \%$ \\
Apr-12 & 4 & 193 & $6.9 \%$ \\
Jul-12 & 4 & 191 & $2.9 \%$ \\
Sep-12 & 4 & 255 & $1.5 \%$ \\
Oct-12 & 5 & 511 & $1.8 \%$ \\
Dec-12 & 4 & 213 & $0.7 \%$ \\
\hline Jan-13 & 3 & 169 & $2.6 \%$ \\
Apr-13 & 3 & 209 & $16.5 \%$ \\
Jul-13 & 3 & 182 & $4.5 \%$ \\
Sep-13 & 2 & 84 & $2.0 \%$ \\
Oct-13 & 10 & 442 & $5.0 \%$ \\
Dec-13 & 11 & 236 & $1.6 \%$ \\
\hline Jan-14 & 5 & 335 & $6.7 \%$ \\
Apr-14 & 4 & 297 & $5.9 \%$ \\
Jul-14 & 3 & 296 & $5.8 \%$ \\
Sep-14 & 3 & 259 & $6.2 \%$ \\
& & & \\
Total & 71 & 4474 & $4.5 \%$ \\
\hline
\end{tabular}


Table 3. Comparison of Jolly-Seber models with different capture probability and survival structures. Model $\mathrm{P}_{\mathrm{t}}$ assumes equal capture probability for rainbow trout previously captured and not previously captured within the trip while $\mathrm{P}_{\mathrm{tb}}$ allows different capture probabilities for these two groups (both models allow capture probability to vary over time). Model $\mathrm{S}_{\mathrm{t}}$ allows different 90-day survival rate estimates across trips while $S_{0}$ assumes equal rates across trips. Rows shaded in dark grey highlight the model with the best out-of-sample predictive power (lowest AIC) within reaches. Rows shaded in light grey highlight the second best model.

\begin{tabular}{|c|c|c|c|c|c|c|c|c|c|c|c|}
\hline \multirow[b]{2}{*}{ Reach } & \multirow[b]{2}{*}{ Model } & \multirow[b]{2}{*}{$\mathbf{L L}$} & \multirow[b]{2}{*}{$\mathbf{K}$} & \multirow[b]{2}{*}{ AIC } & \multirow[b]{2}{*}{ c-hat } & \multirow[b]{2}{*}{$\tau$} & \multirow[b]{2}{*}{$\Delta \mathrm{AIC}$} & \multicolumn{4}{|c|}{ Across-Trip Average } \\
\hline & & & & & & & & $\mathbf{N}$ & S90 & pCapV & pCapR \\
\hline \multirow[t]{4}{*}{ I } & $\mathrm{P}_{\mathrm{t}}-\mathrm{S}_{\mathrm{o}}$ & -445 & 35 & 961 & 5.8 & 3.2 & 78 & 19,861 & 0.73 & 0.03 & 0.03 \\
\hline & $\mathrm{P}_{\mathrm{tb}}-\mathrm{S}_{\mathrm{o}}$ & -408 & 36 & 888 & 2.9 & 2.0 & 5 & 33,903 & 0.81 & 0.02 & 0.06 \\
\hline & $\mathrm{P}_{\mathrm{t}}-\mathrm{S}_{\mathrm{t}}$ & -436 & 44 & 961 & 5.6 & 2.8 & 78 & 19,787 & 0.75 & 0.04 & 0.04 \\
\hline & $\mathrm{P}_{\mathrm{tb}}-\mathrm{S}_{\mathrm{t}}$ & -396 & 45 & 883 & 2.6 & 1.7 & 0 & 33,661 & 0.87 & 0.02 & 0.06 \\
\hline \multirow[t]{4}{*}{ II } & $\mathrm{P}_{\mathrm{t}}-\mathrm{S}_{\mathrm{o}}$ & -494 & 35 & 1058 & 4.4 & 3.4 & 135 & 11,967 & 0.76 & 0.07 & 0.07 \\
\hline & $\mathrm{P}_{\mathrm{tb}}-\mathrm{S}_{\mathrm{o}}$ & -429 & 36 & 930 & 1.6 & 1.4 & 7 & 18,534 & 0.81 & 0.04 & 0.11 \\
\hline & $\mathrm{P}_{\mathrm{t}}-\mathrm{S}_{\mathrm{t}}$ & -483 & 44 & 1054 & 4.2 & 2.8 & 131 & 11,164 & 0.71 & 0.08 & 0.08 \\
\hline & $\mathrm{P}_{\mathrm{tb}}-\mathrm{S}_{\mathrm{t}}$ & -417 & 45 & 923 & 1.5 & 1.1 & 0 & 17,790 & 0.80 & 0.04 & 0.11 \\
\hline \multirow[t]{4}{*}{ III } & $\mathrm{P}_{\mathrm{t}}-\mathrm{S}_{\mathrm{o}}$ & -477 & 35 & 1024 & 4.2 & 3.3 & 78 & 5,353 & 0.69 & 0.09 & 0.09 \\
\hline & $\mathrm{P}_{\mathrm{tb}}-\mathrm{S}_{\mathrm{o}}$ & -454 & 36 & 980 & 3.2 & 2.7 & 34 & 7,047 & 0.73 & 0.06 & 0.13 \\
\hline & $\mathrm{P}_{\mathrm{t}}-\mathrm{S}_{\mathrm{t}}$ & -454 & 44 & 996 & 3.4 & 2.3 & 51 & 5,108 & 0.66 & 0.10 & 0.10 \\
\hline & $\mathrm{P}_{\mathrm{tb}}-\mathrm{S}_{\mathrm{t}}$ & -428 & 45 & 946 & 2.1 & 1.7 & 0 & 6,714 & 0.73 & 0.07 & 0.13 \\
\hline \multirow[t]{4}{*}{$\mathrm{IVa}$} & $\mathrm{P}_{\mathrm{t}}-\mathrm{S}_{\mathrm{o}}$ & -461 & 35 & 992 & 5.3 & 3.8 & 75 & 2,186 & 0.86 & 0.11 & 0.11 \\
\hline & $\mathrm{P}_{\mathrm{tb}}-\mathrm{S}_{\mathrm{o}}$ & -422 & 36 & 917 & 2.4 & 2.1 & 0 & 2,639 & 0.87 & 0.07 & 0.20 \\
\hline & $\mathrm{P}_{\mathrm{t}}-\mathrm{S}_{\mathrm{t}}$ & -449 & 44 & 985 & 4.8 & 3.1 & 68 & 1,914 & 0.79 & 0.13 & 0.13 \\
\hline & $\mathrm{P}_{\mathrm{tb}}-\mathrm{S}_{\mathrm{t}}$ & -415 & 45 & 920 & 2.3 & 1.9 & 3 & 2,367 & 0.82 & 0.08 & 0.21 \\
\hline \multirow[t]{4}{*}{$\mathrm{IVb}$} & $\mathrm{P}_{\mathrm{t}}-\mathrm{S}_{\mathrm{o}}$ & -692 & 68 & 1520 & 3.0 & 1.4 & 102 & 713 & 0.52 & 0.11 & 0.11 \\
\hline & $\mathrm{P}_{\mathrm{tb}}-\mathrm{S}_{\mathrm{o}}$ & -642 & 69 & 1422 & 1.3 & 1.2 & 4 & 1,093 & 0.59 & 0.07 & 0.15 \\
\hline & $\mathrm{P}_{\mathrm{t}}-\mathrm{S}_{\mathrm{t}}$ & -683 & 77 & 1521 & 2.9 & 1.4 & 102 & 713 & 0.53 & 0.12 & 0.12 \\
\hline & $\mathrm{P}_{\mathrm{tb}}-\mathrm{S}_{\mathrm{t}}$ & -631 & 78 & 1419 & 1.3 & 1.1 & 0 & 1,168 & 0.65 & 0.07 & 0.15 \\
\hline
\end{tabular}

$\mathrm{LL}=\log$ likelihood; $\mathrm{K}=$ number of estimated parameter; $\mathrm{AIC}=$ Akaike Information Criteria; c-hat $=\chi^{2} /$ degrees of freedom; $\tau=$ estimated variance-to-mean ratio (overdispersion) from negative 
binomial error model; $\triangle \mathrm{AIC}=$ difference in $\mathrm{AIC}$ for each model relative to model with lowest AIC; $\mathrm{N}=$ average abundance across trips; $\mathrm{S} 90=$ average 90 -day survival rate across trips; $\mathrm{pCapV}=$ average across-trip capture probability on $2^{\text {nd }}$ pass $; \mathrm{pCapR}=$ average within-trip capture probability on $2^{\text {nd }}$ pass. 
Table 4. Estimates of the proportion of marks released in the robust design sections of each reach (see Fig. 1) that remain in that section (residency proportion) on the same trip as the initial release (within trip), one trip after the initial release trip, and two or more trips after the initial release trip. Residency estimates are based on computations using the spatial distribution of marked rainbow trout that are released and the modelled Cauchy distribution of movement distances.

\begin{tabular}{lcccccc}
\hline \multicolumn{1}{c}{ Residency Proportion (pRes) } & I & II & III & IVa & IVb & Average \\
\hline Within Trip & 0.92 & 0.81 & 0.83 & 0.88 & 0.81 & 0.85 \\
One trip after initial release trip & 0.90 & 0.71 & 0.77 & 0.79 & 0.70 & 0.77 \\
More than one trip after initial release trip & 0.85 & 0.56 & 0.67 & 0.70 & 0.65 & 0.69 \\
\hline
\end{tabular}


Table 5. The number of across-reach rainbow trout recaptures by release and recapture reach using all the data (a) and a subset from downstream trips only (b), and the mean of posterior distributions estimating the percent of marked trout moving between reaches based on the across-reach movement model (c). The number and percent of marked trout recaptured in reaches other than the release reach are shown in the two rightmost columns for a) and b). In c), the rightmost column represents the estimated percent of marked trout that moved to reaches IVa or IVb.

a) Number of recaptures (fall Glen Canyon (GLC) and downstream trips)

\begin{tabular}{|c|c|c|c|c|c|c|c|c|}
\hline & & \multicolumn{5}{|c|}{ Recapture Reach } & \multicolumn{2}{|c|}{ Outside of Release Reach } \\
\hline & & GLC & II & III & IVa & $\mathbf{I V b}$ & \# of Recaps & $\%$ of Recaps \\
\hline \multirow{5}{*}{$\begin{array}{c}\text { Release } \\
\text { Reach }\end{array}$} & GLC & 2228 & 8 & 1 & 0 & 2 & 11 & $0.5 \%$ \\
\hline & II & 13 & 1999 & 12 & 8 & 6 & 39 & $1.9 \%$ \\
\hline & III & 1 & 8 & 2087 & 10 & 7 & 26 & $1.2 \%$ \\
\hline & IVa & 0 & 0 & 2 & 1153 & 67 & 69 & $5.6 \%$ \\
\hline & IVb & 1 & 0 & 1 & 11 & 541 & 13 & $2.3 \%$ \\
\hline
\end{tabular}

b) Number of recaptures (downstream trips only)

\begin{tabular}{ccccccccc}
\hline & & \multicolumn{3}{c}{ Recapture Reach } & \multicolumn{3}{c}{ Outside of Release Reach } \\
& & I & II & III & IVa & IVb & \# of Recaps & \% of Recaps \\
\hline \multirow{3}{*}{ Release } & I & 784 & 0 & 0 & 0 & 2 & 2 & $0.3 \%$ \\
Reach & III & 7 & 1999 & 12 & 8 & 6 & 33 & $1.6 \%$ \\
& IVa & 0 & 0 & 2087 & 10 & 7 & 25 & $1.2 \%$ \\
& IVb & 1 & 0 & 1 & 11 & 541 & 13 & $5.6 \%$ \\
\hline
\end{tabular}

c) Estimates of the mean percentage moving from release to recapture reach

\begin{tabular}{ccccccccc}
\hline & & \multicolumn{4}{c}{ Recapture Reach } & \multicolumn{3}{c}{ Outside of Release Reach } \\
& & I & II & III & IVa & IVb & All & IVa+IVb \\
\hline \multirow{3}{*}{ Release } & I & 99.87 & 0.08 & 0.02 & 0.01 & 0.01 & 0.13 & 0.02 \\
Reach & III & 0.49 & 98.67 & 0.57 & 0.14 & 0.12 & 1.33 & 0.27 \\
& IVa & 0.02 & 0.24 & 99.30 & 0.24 & 0.17 & 0.70 & 0.41 \\
& IVb & 0.00 & 0.06 & 0.23 & 91.88 & 7.81 & 8.12 & \\
\hline
\end{tabular}




\section{Figure Captions}

Figure 1. Map of the study area. Numbers beside the mainstem Colorado River denote river kilometers (thalweg distance) downstream from Glen Canyon Dam (GCD).

Figure 2. Map of reach II, showing the location of 250-m shoreline sites and areas sampled on nights 1 and 2 of each trip. Note the robust design section located in the central $2 \mathrm{~km}$ of reaches I-III is sampled on both nights, while buffer zones located at the upstream and downstream $2 \mathrm{~km}$ of the reach are sampled only once per trip.

Figure 3. Length Frequencies of rainbow trout by reach for each downstream sampling trip. The size of the circles is proportional to the relative catch of each 10-mm size class within a trip. Results for reach $\mathrm{IVb}$ are based on all catch and a subset of catch based on normal speed electrofishing only, which is the method used in other reaches.

Figure 4. Estimates of abundance of rainbow trout by reach and trip based on model $\mathrm{P}_{\mathrm{tb}}-\mathrm{S}_{\mathrm{t}}$. Points represent maximum likelihood estimates and vertical bars represent 1 standard deviation.

Figure 5. Interpolated abundance of rainbow trout over the study area from Glen Canyon dam (river $\mathrm{km} 0$ ) to the bottom of reach IVb (river km 130) by trip. Reach-specific abundance estimates used for the interpolation were based on model $\mathrm{P}_{\mathrm{tb}}-\mathrm{S}_{\mathrm{o}}$.

Figure 6. Estimates of the 90-day survival rate and relative immigration rate of rainbow trout by reach based on model $\mathrm{P}_{\mathrm{tb}}-\mathrm{S}_{\mathrm{t}}$. The relative immigration rate is the number of immigrants per resident, computed as the ratio of recruitment between trip intervals to abundance at the end of the interval, averaged across all trip intervals. Points represent maximum likelihood estimates and vertical lines denote 1 standard deviation. The gray hashed box in the top plot represents survival measured in other systems (see text) computed from the reported Von Bertalanffy growth coefficients $(\mathrm{K})$ assuming instantaneous annual mortality $=1.5-1.63 \cdot \mathrm{K}$. The black dashed line represents the average 90-day survival across reaches. The gray dashed line represents the expected survival rate given the estimated growth coefficient for rainbow trout in Grand Canyon (Yard et al., this issue). 
Figure 7. Some example plots (reach II and IVa for 3 trip intervals) showing the fit of Cauchy distributions (black lines) to observed movement distances weighted by the probability of observing those movement distances given the sampling design (bars). The height of each bar is the proportion of rainbow trout recaptured in each $0.25-\mathrm{km}$ movement distance increment. The sample size (n) for each example is also shown.

Figure 8. Cauchy distributions of movement distances between adjacent trips by reach. The height of each line represents the proportion of rainbow trout recaptured in each $0.25-\mathrm{km}$ movement distance increment. Cauchy distributions were fitted to observations corrected for differences in the probability of detecting various movement distances given the sampling design (see Appendix).

Figure 9. Components of across-reach movement model (a-c) leading to predictions of rainbow trout immigration to reaches upstream (IVa) and downstream (IVb) of the Little Colorado River (LCR) confluence, which are compared direct estimates of recruitment in these reaches from the Jolly-Seber model (d). Plot a) shows the mean (solid line) and 95\% credible intervals (dashed lines) of the estimated river wide abundance for one of 11 trips (July 2014) based on interpolation and the estimates of abundance from the Jolly-Seber model (points). Plot b) shows the Cauchy movement distributions for reaches upstream of IVa and IVb estimated from acrossreach movement data. The reach-specific curves are based on the means of the posterior distributions of location and scale parameters and represent movement for the vertical sections defined in a) to LCR reaches. Plot c) shows the mean movement distribution for reach II (solid line) and the $95 \%$ credible intervals (dashed lines) as an example of uncertainty in the movement distribution. Plot d) compares the predicted immigration to reaches IVa and IVb based on upstream abundance and movement distributions as determined by the across-reach movement model (U), with independent estimates of immigration from the Jolly-Seber model applied to data for IVa and IVb (W). The total height of the bars represents the mean values and the error bars denote the $95 \%$ credible intervals. The height of the shaded bars for predictions based on upstream sources $(\mathrm{U})$ represents the contribution from upstream sections as defined by their distance from Glen Canyon Dam in the legend (dashed vertical lines in a). 


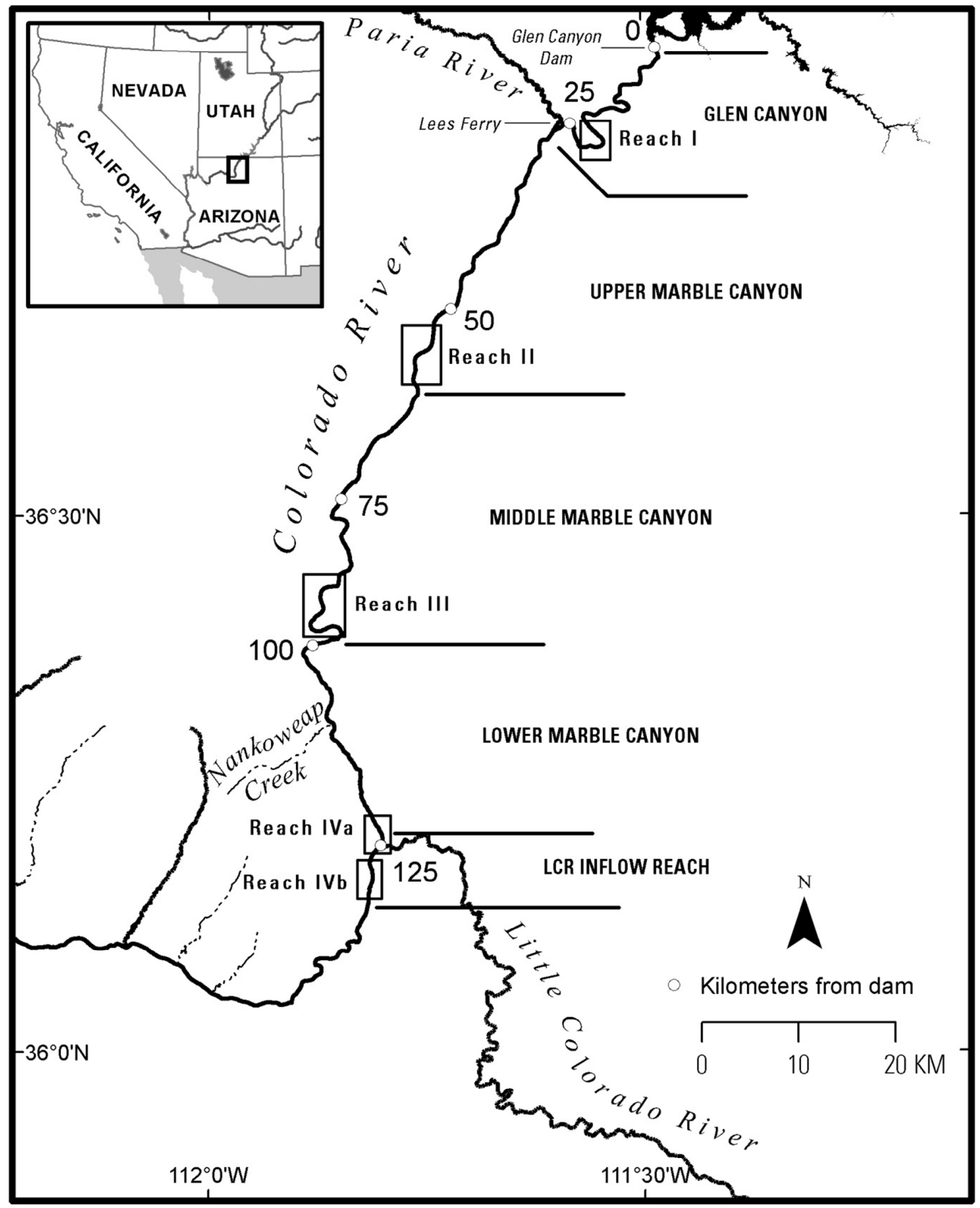

Figure 1. 


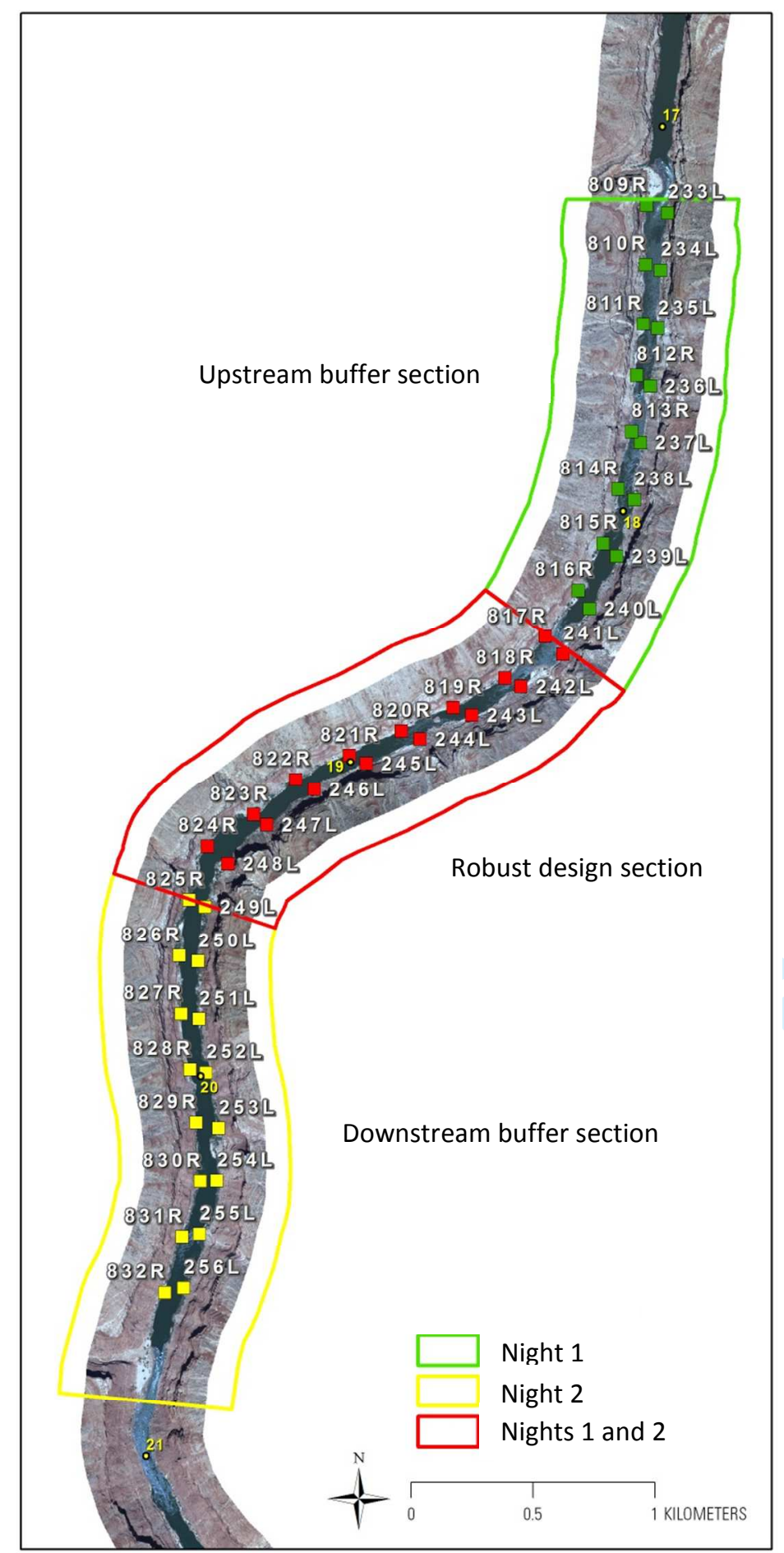

Figure 2. 

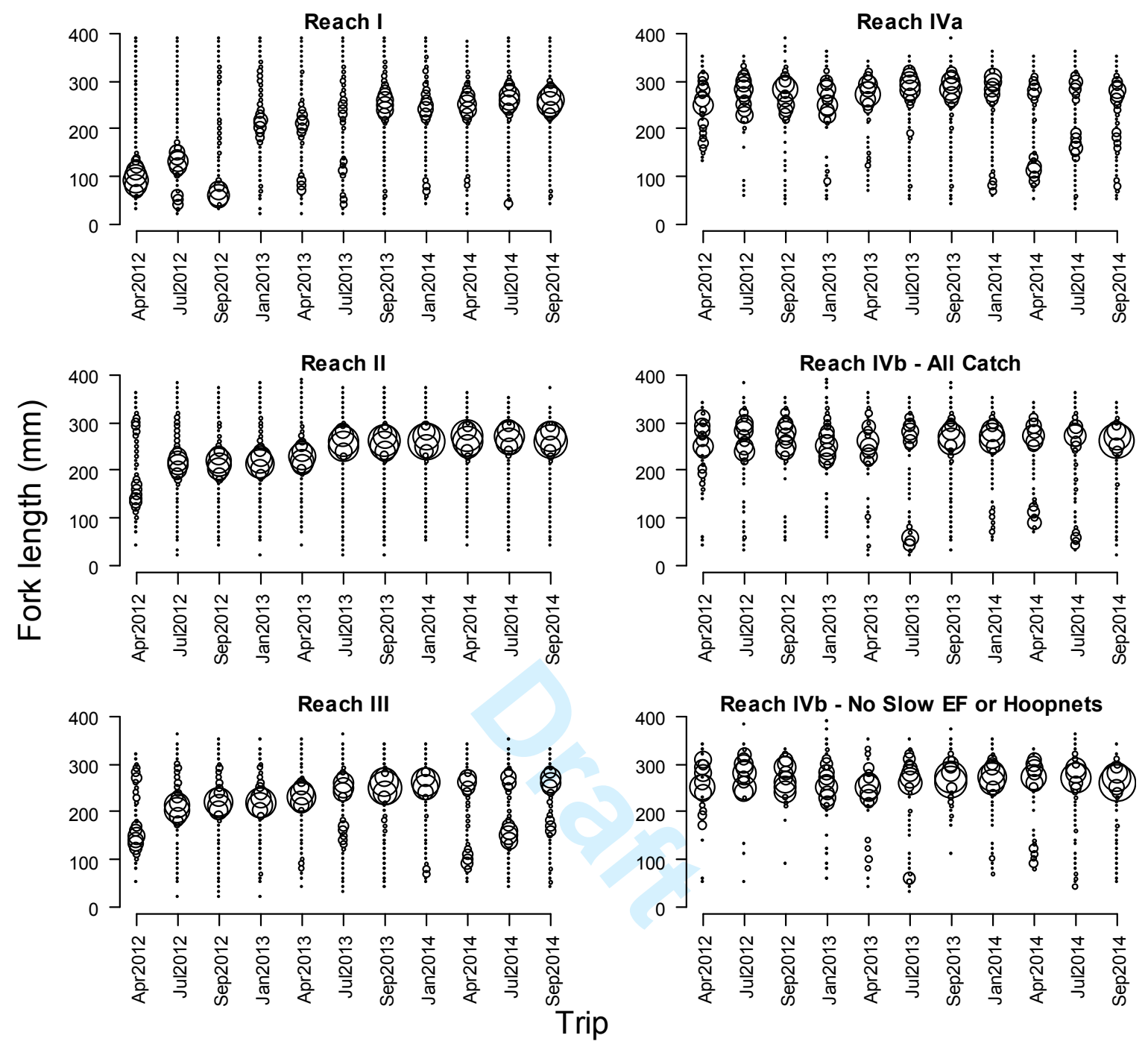

Figure 3. 


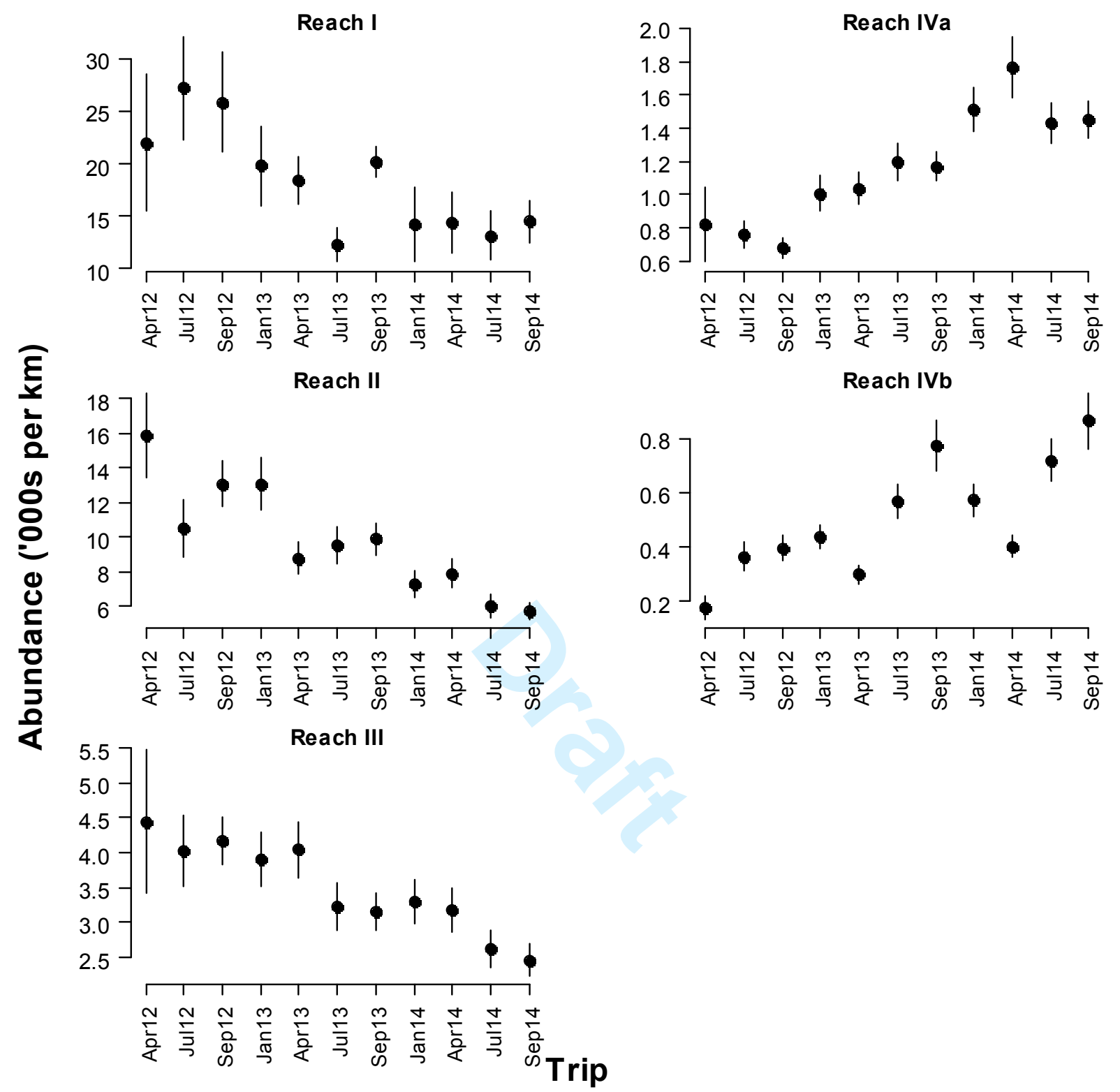

Figure 4. 


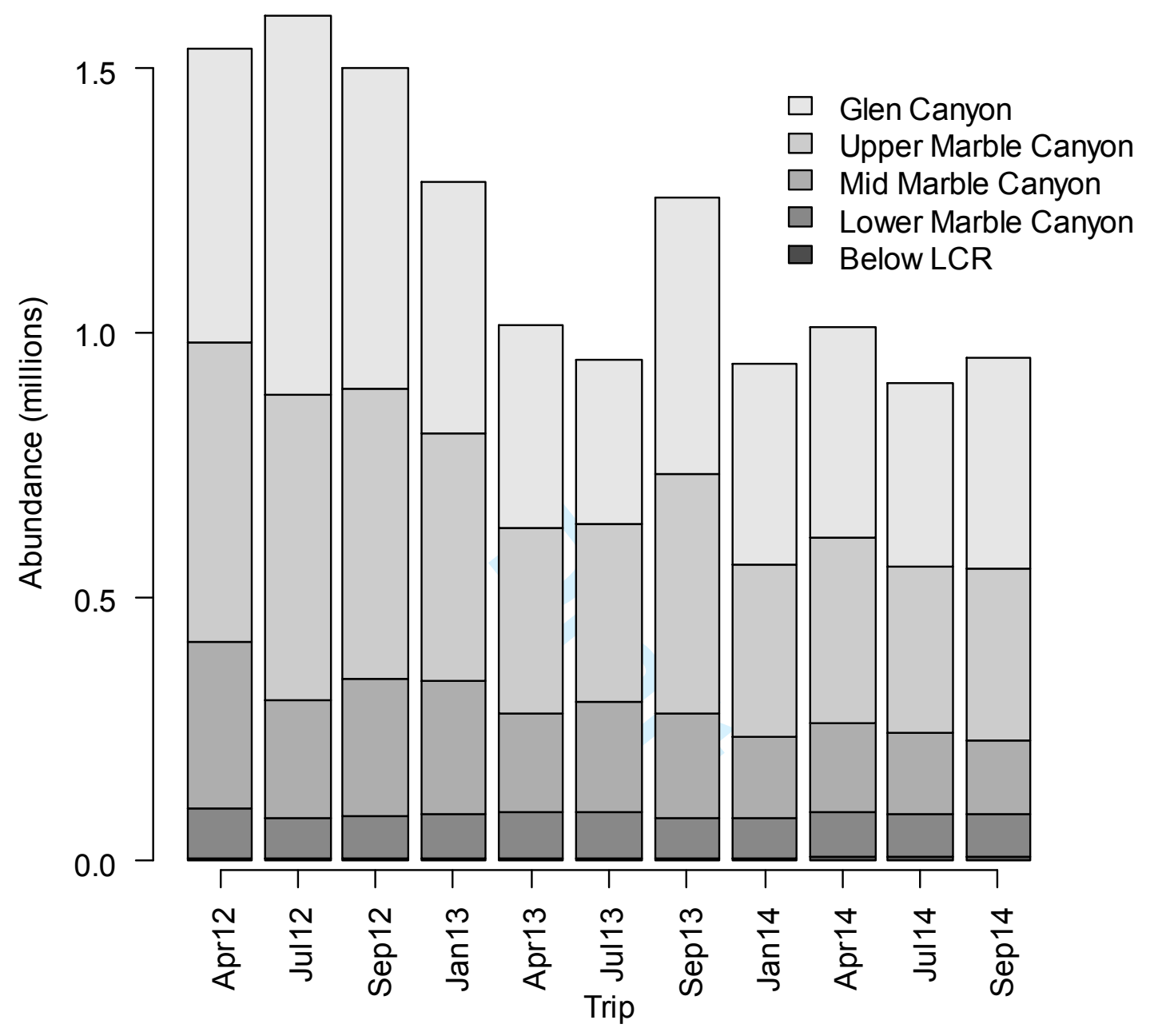

Figure 5. 

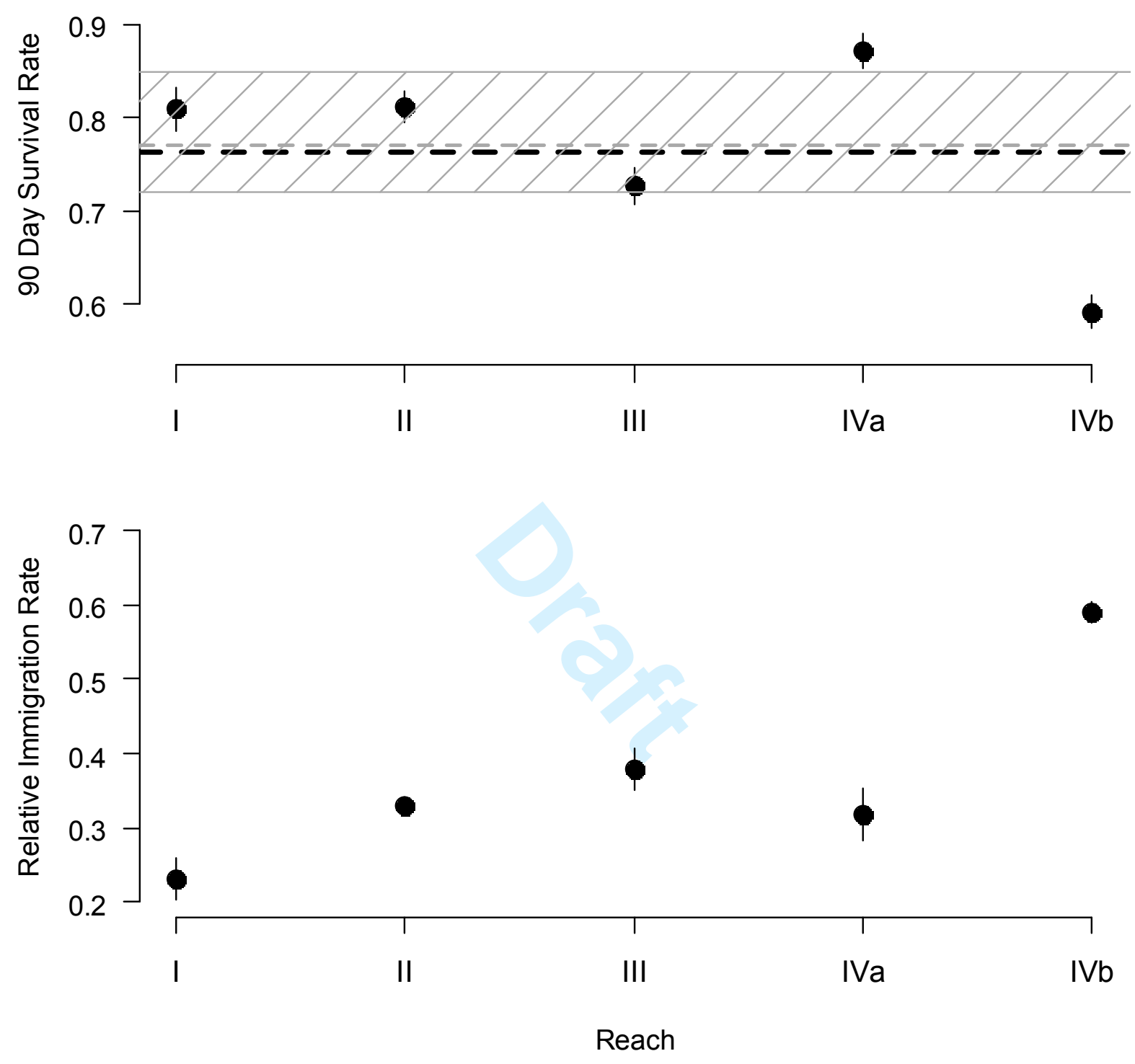

Figure 6. 


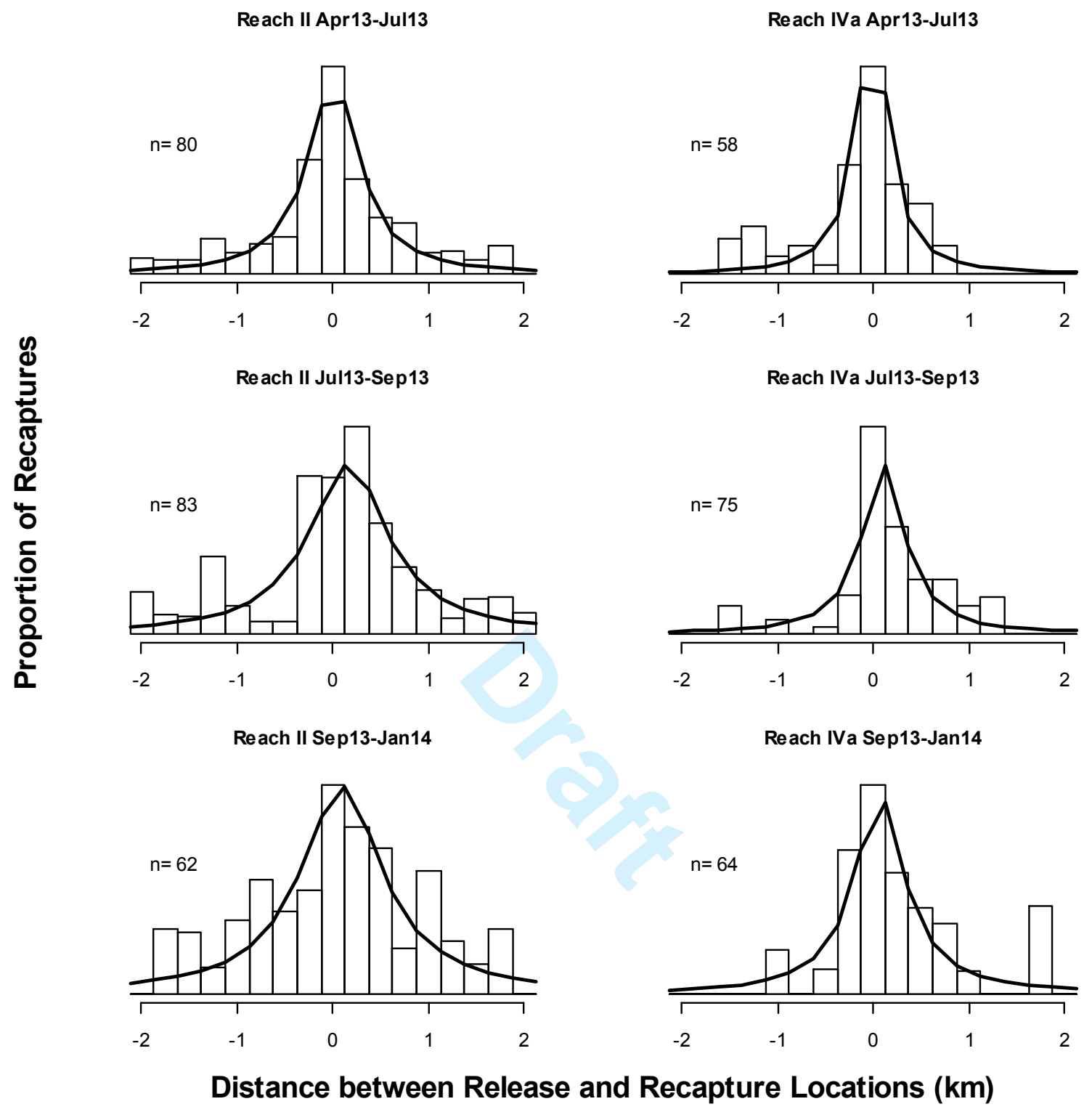

Figure 7. 


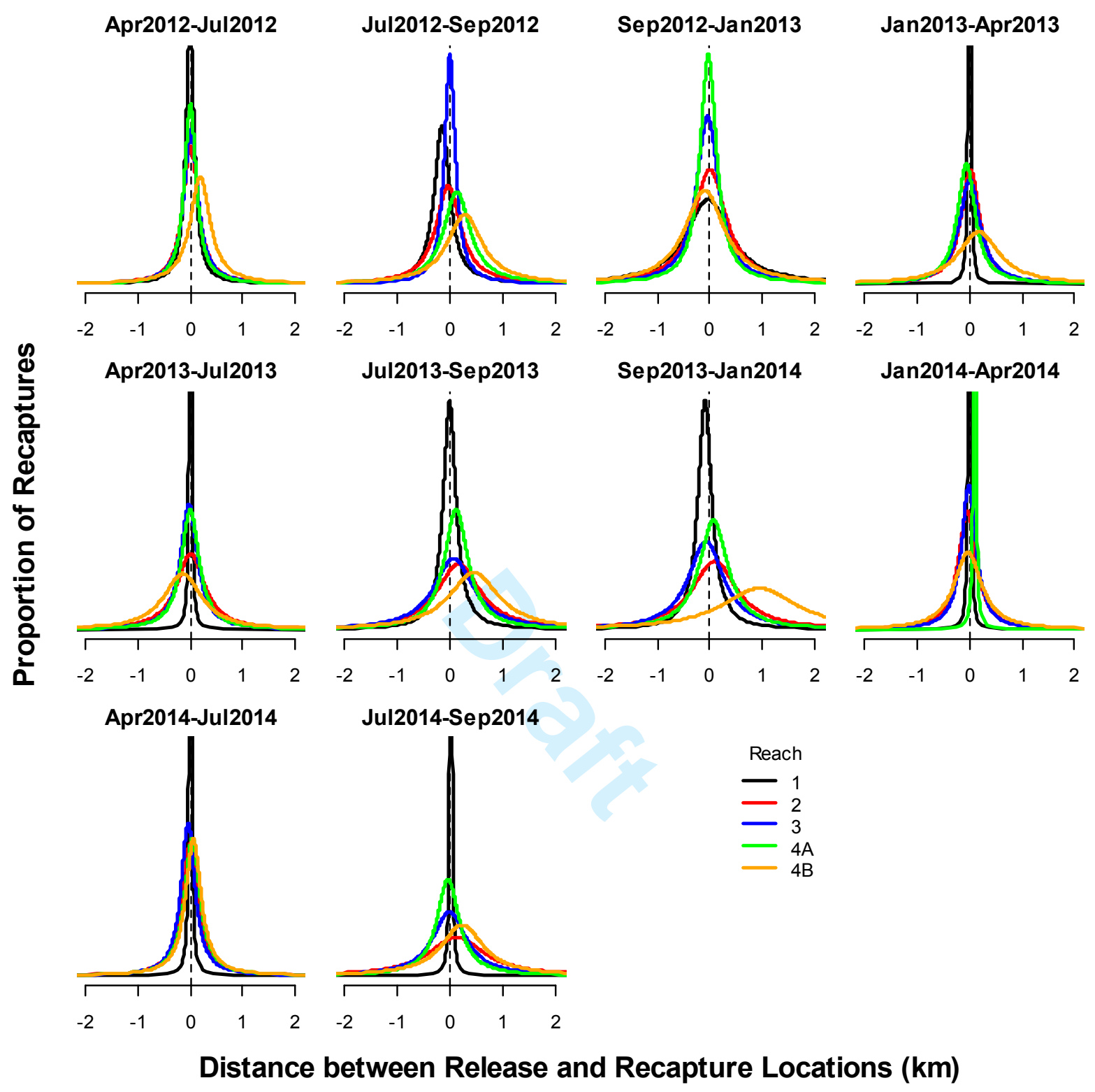

Figure 8. 


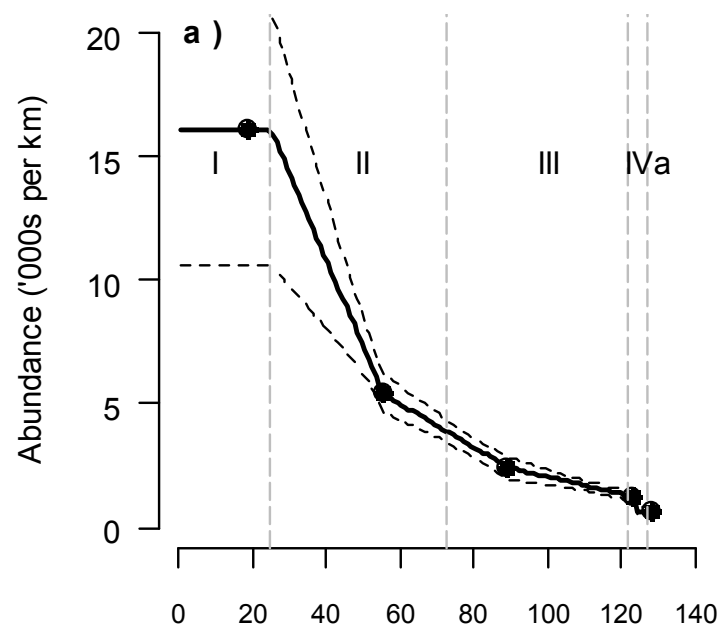

Distance from Glen Canyon Dam (km)

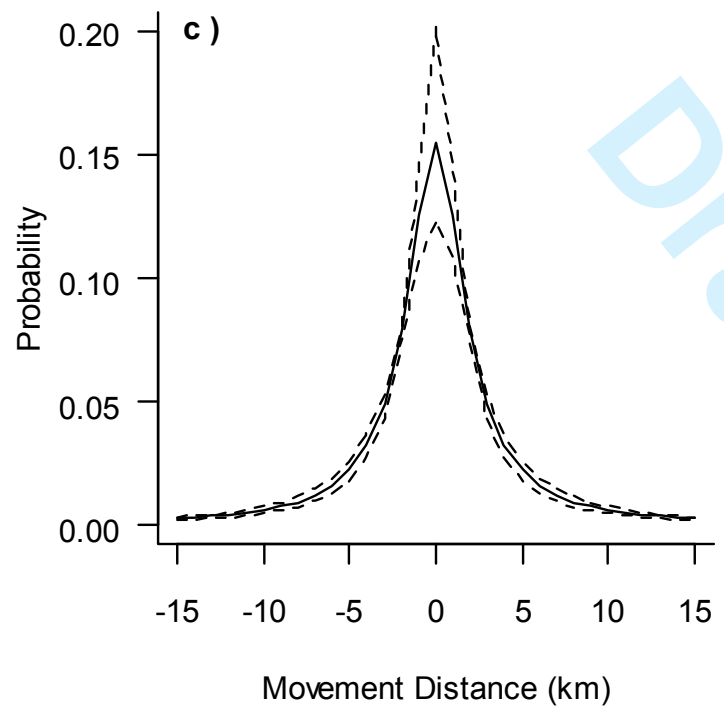

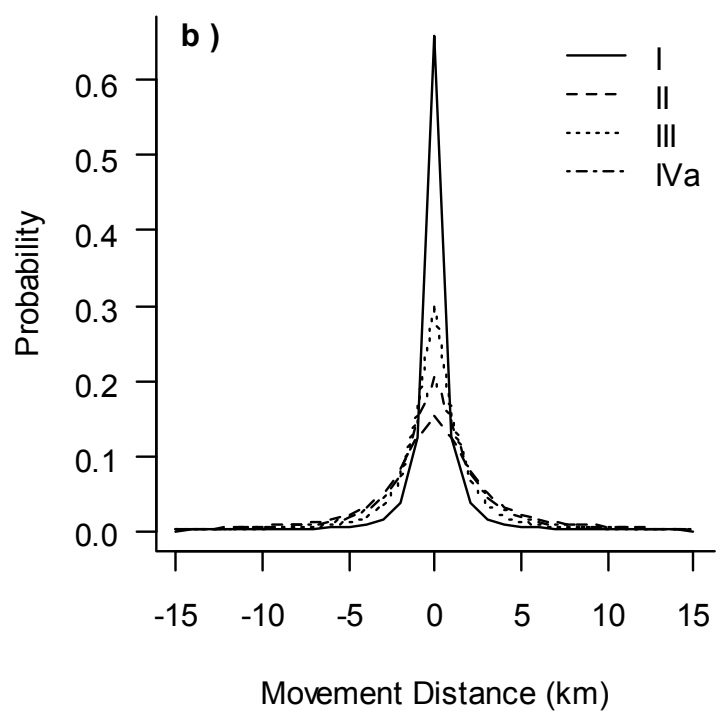

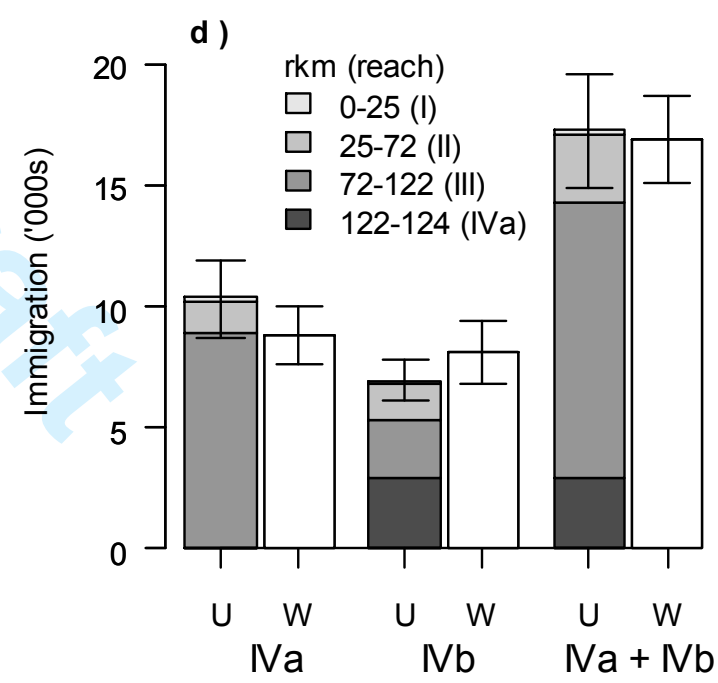

Figure 9. 


\section{Appendix - Computation and Effect of Movement Distance Observation Probabilities}

An observed distribution of movement distances will be determined by the underlying true movement distribution and a variety of factors that influence the ability to detect each movement distance. In our study, factors that affect the latter include the distribution of marks released across sites in a reach, variation in sampling effort among sites in a reach (number of passes), and variation in capture probabilities over trips and among reaches. For example, in reaches I-III, we sample 2-km buffer zones upstream and downstream of the central 2-km robust design section where marks were released (Fig. 2). This spatial layout allows us to detect withinreach movements up to $4 \mathrm{~km}$, but the opportunity to detect shorter movements is greater than for larger ones owing to the additional effort ( 2 passes) in the central $2-\mathrm{km}$ section. Of the $16250-\mathrm{m}$ sampling sites within the robust design sections, there are 16 possibilities of observing no movement through movement distances of up to $2 \mathrm{~km}$. However, movements of $4 \mathrm{~km}$ can only be detected based on releases from sites at the upstream and downstream boundaries of the robust design sections (4 of 16). In this example, we are four-times less likely to detect a movement distance of $4 \mathrm{~km}$ compared to detecting distances of $0-2 \mathrm{~km}$. The situation is further complicated by the fact that two passes of sampling effort is conducted in the robust design section but only one pass is conducted in buffer zones, which reduces the probability of detecting larger movements compared to shorter ones. There will also be minor differences in the probability of detecting various movement distances for each release and recapture trip combination owing to variation in the number of releases across sites and differences in capture probability over trips and passes.

To remove effects of mark distribution, sampling design, and capture probability on predicted movement distributions, estimates of movement distance distributions must be calculated from the raw observed distances weighted by the inverse of observation probability of observing these distances (pOMD). This appendix describes how pOMD values are computed and shows how they vary across reaches and trips, and their effect on movement distance distributions.

We computed the pOMD values across the full range of observable movement distances over the study area $(\sim-130 \mathrm{~km}$ to $130 \mathrm{~km}$ in $0.25 \mathrm{~km}$ increments, where negative and positive values indicate upstream and downstream movement, respectively) as follows: 
1. Compute the probability of capturing a fish in each site 's_recap' across passes ' $j$ ' to Npasses $_{s}$ on trip 'i_recap' $\left(p_{s, i}\right)$ based on reach (r)-, trip (i)-, and pass (j)- specific capture probabilities estimated from the Jolly-Seber model $\left(\mathrm{pCap}_{\mathrm{r}, \mathrm{i}, \mathrm{j}}\right)$ using,

(A1) $\quad p_{s_{-} \text {recap }, i_{-} \text {recap }}=1-\prod_{j=1}^{j=\text { Npasses }_{s}} 1-p \operatorname{Cap}_{r, i, j}$

This equation accounts for different capture probabilities per pass among reaches, trips, and passes, as well as different levels of effort (passes) by site depending on whether they are within the robust design section ( 2 passes) or not (1 pass) for reaches I-III. The equation also accounts for differences in effort among reaches (e.g., a maximum of 2 passes in reaches I_IVa vs. 5 passes for reach IVb). Note that all sites within a reach are assumed to have the same capture probability estimated for the reach for each trip and pass.

2. The relative probability of capturing tags ( $\mathrm{rp})$ released in site 's_rel' on release trip 'i_rel' in site 's_recap' on a later trip 'i_recap' is computed using,

(A2) $r p_{s_{-} r e l, s_{-} r e c a p, i_{-} r e l, i_{-} r e c a p}=M_{s_{-} r e l, i_{-} r e l} \cdot p_{s_{-} \text {recap }, i_{-} r e c a p,}$

where $\mathrm{M}_{\mathrm{s}_{-} \text {rel, }}$ _rel are the number of marks released. Note here that relative probabilities for a given release-recapture site combination will be higher when the number of marks released is higher or when the recapture probability in the recapture site is higher.

3. The probability of observing a particular movement distance is then calculated as:

$$
p O M D_{d, i_{-} \text {rel,i_recap }}=\frac{\sum r p_{s_{-} r e l, s_{-} \text {recap }, i_{-} \text {rel, } i_{-} \text {recap }}}{\sum_{d} p O M D_{d_{, i_{-}} \text {rel,i_recap }}}
$$

where ' $d$ ' represent an index of the $0.25 \mathrm{~km}$ longitudinal distance increment between release (s_rel) and recapture sites (s_recap), and the nominator is restricted to all site combinations that are separated by a distance included within ' $d$ '. 
Examples of the pOMD patterns across the full range of possible movement distances for various release and recovery trip combinations are provided in Figure S1.1. Four types of pOMD patterns are apparent depending on the type of release and recovery trip:

\section{Release Trip: $\quad$ Full Glen Canyon \\ Recovery Trip: $\quad$ Downstream \\ Example: $\quad$ Nov2011-Apr2012 (Fig. Ala)}

- Detection of large upstream movements $>25 \mathrm{~km}$ are not possible given that all marks are released in the upper $25 \mathrm{~km}$ of the study area;

- There are relatively small gaps of unobservable movement distances ( 0 probabilities) owing to the continuous nature of release locations over the entire $25 \mathrm{~km}$ of Glen Canyon. However, as the length of Glen Canyon is slightly less than the distance among reaches on downstream trips, some gaps remain;

- The probability of observing larger movement distances is higher owing to higher capture probabilities in reaches IVa and IVb.

$\begin{array}{ll}\text { Release Trip: } & \text { Full Glen Canyon } \\ \text { Recovery Trip: } & \text { Full Glen Canyon } \\ \text { Example: } & \text { Nov2011-Oct2013 (Fig. A1b) }\end{array}$

- Owing to the continuous distribution of both marks released across sites on the first trip and the recovery effort on the second trip, the pOMD pattern is much more continuous than the previous example;

- Movement detection probabilities decline from a maximum at the $-0.125-0.125 \mathrm{~km}$ movement increment to zero at the $+/-25 \mathrm{~km}$ movement increment owing to edge effects; and

- Detecting movement distances $>25 \mathrm{~km}$ upstream or downstream is not possible owing to the fact that sampling on these trips is restricted to Glen Canyon. 
Release Trip: $\quad$ Downstream

Recovery Trip: $\quad$ Downstream

Example: $\quad$ Apr2012-Jul2012 (Fig. A1c)

- Large upstream and downstream movement distances are potentially observable, but the probability of detecting downstream movement is higher owing to greater capture probability in more downstream reaches combined with a larger number of releases in upstream reaches;

- Within a reach, there is a much higher probability of detecting smaller movement distances than larger ones owing to edge effects and reduced effort in sites outside of robust design sections; and

- There is zero probability of detecting movement distances approximately equal to the distance between reaches less the length of the reaches as no sampling is conducted between reaches. 


$\begin{array}{ll}\text { Release Trip: } & \text { Downstream } \\ \text { Recovery Trip: } & \text { Full Glen Canyon } \\ \text { Example: } & \text { Apr2012-Oct2012 (Fig. Alc) }\end{array}$

- Compared to other trip combinations, the probability of detecting large upstream movements is highest owing to full coverage of Glen Canyon on the recovery trip.

- The probabilities of detecting the longest upstream movement distances are lower owing to fewer marks being released in the most downstream reach combined with lower capture probability in the most upstream reach.

The weighted movement distribution had a higher proportion of larger movement distances because the weight on greater distances is larger as the probability of observing them given our sampling design is lower (Fig. A2). However, in spite of differences in effort and capture probability among reaches, and variation in effort within reaches, weighting observed movement distances by their probabilities of observation only had a modest effect on statistics describing movement distance distributions. For example, the frequency distribution of uncorrected movement distances based on all across-trip recaptures has a $95 \%$ credible interval of -1.9 to $3.2 \mathrm{~km}$ with a mean of $0.30 \mathrm{~km}$ (Fig A2, top). The distribution based on weighted observations has a $95 \%$ credible interval of -2.6 to $5.1 \mathrm{~km}$ and mean of $0.45 \mathrm{~km}$ (Fig. A2, bottom). The weighted and unweighted distributions were similar because most observed movement distances were very small and within the robust design section, and were therefore not affected by sampling design and differences in capture probability among reaches. 


\section{Appendix Figure Captions}

Figure A1. Example of relative probability of observing movement distances for a sample of release and recapture trip combinations. Negative and positive distances indicate upstream and downstream movement, respectively. Factors that influence the probabilities include the spatial pattern where marks are released (during release trip), where sampling for potential recoveries is conducted (during recovery trip), the frequency of sampling at each location (1, 2, or 5 passes), and differences in capture probabilities among reaches and passes.

Figure A2. Comparison of frequency distributions of movement distances using the raw observed movement distances (top) and where movement distances have been weighted by the inverse of the probability of observing various movement distances (bottom). The height of the bars is proportional to the frequency of each $0.5 \mathrm{~km}$ movement distance class. 


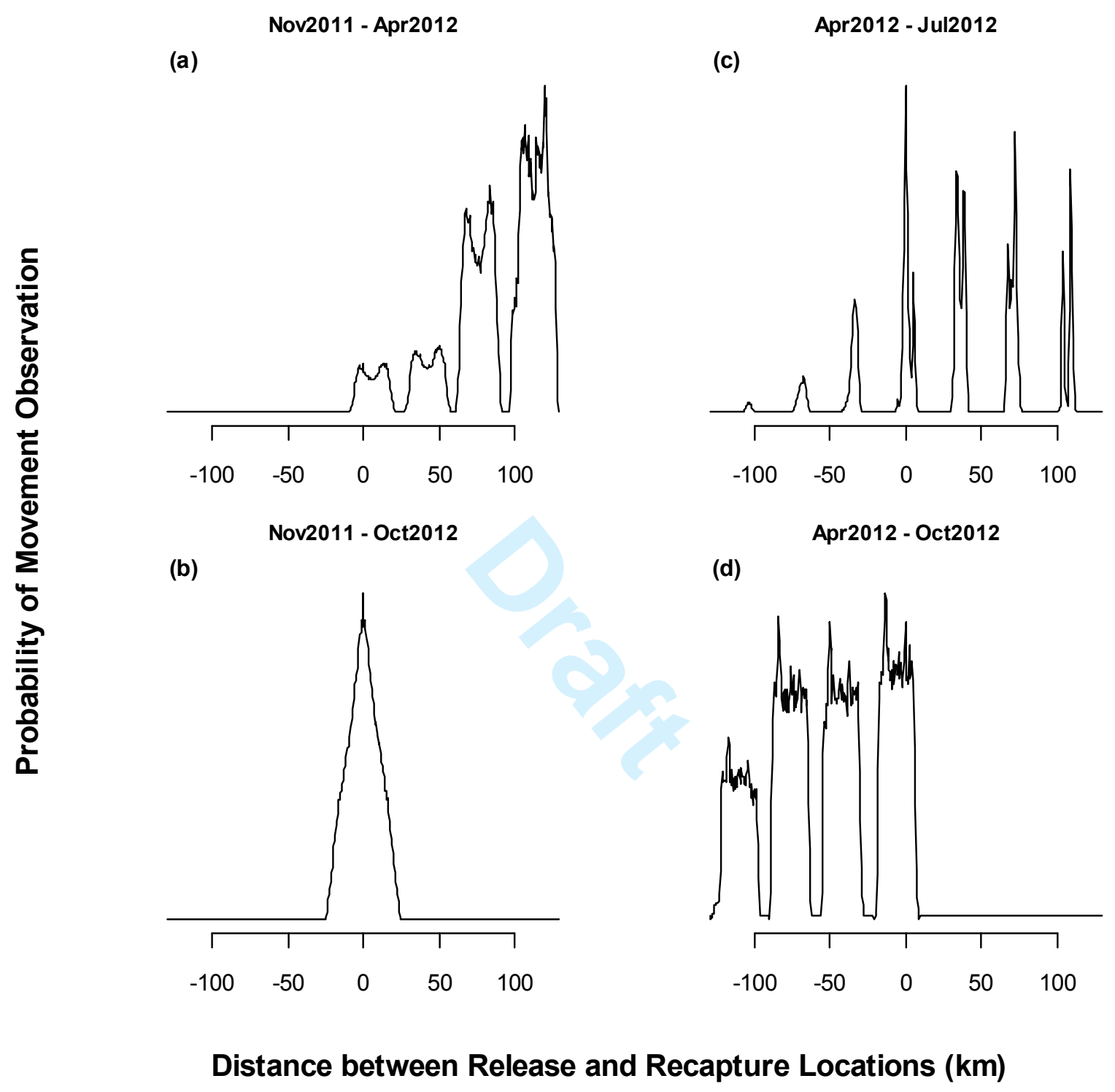

Figure. A1. 

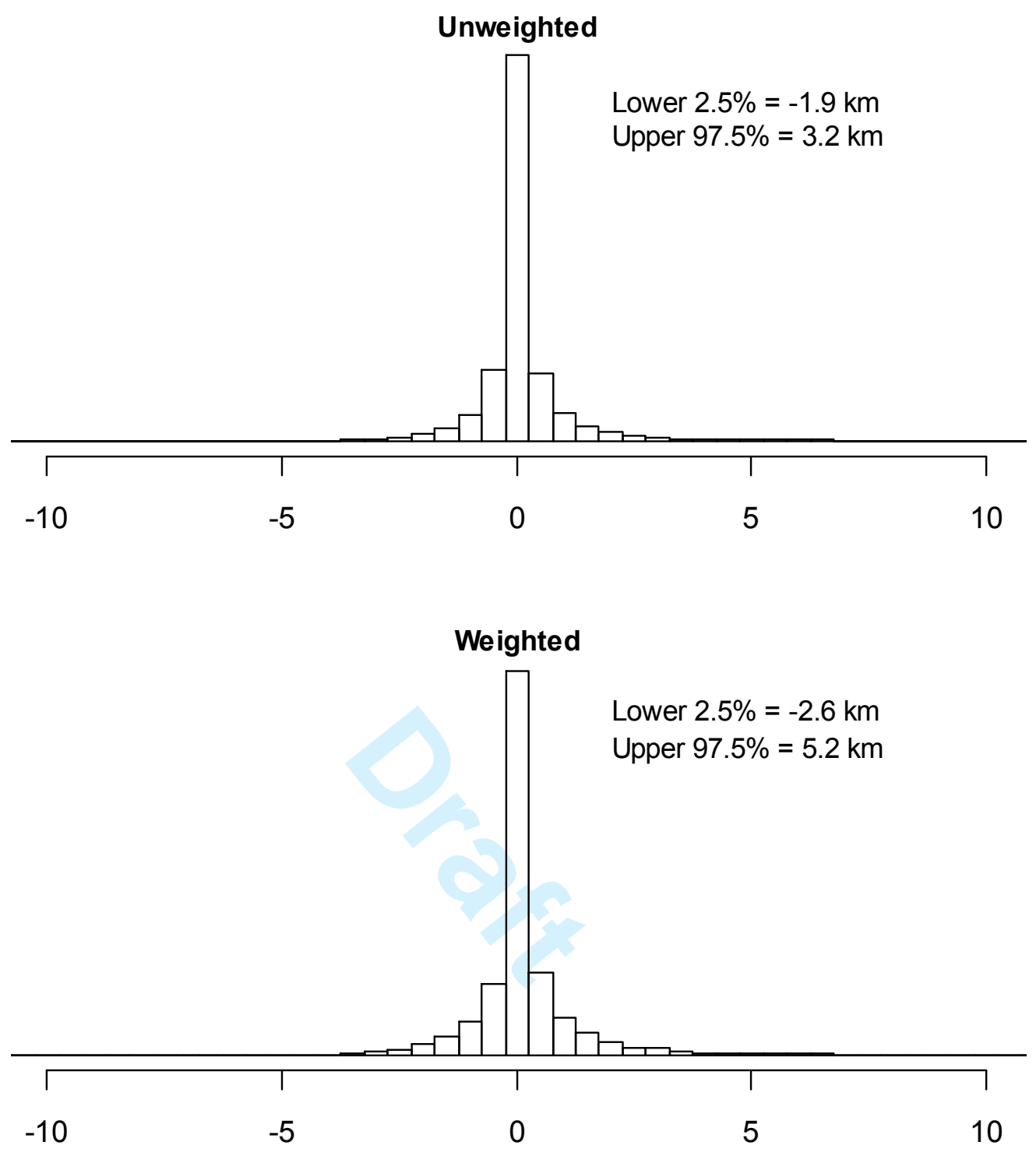

Distance between release and recapture locations $(\mathrm{km})$

Figure A2. 